\title{
Economic models of price competition between traditional and online retailing under showrooming
}

\author{
Subrata Mitra
}

Accepted: 21 October 2021/Published online: 18 November 2021

(C) Indian Institute of Management Calcutta 2021

\begin{abstract}
Showrooming is a phenomenon when a customer views a product at a physical store, but buys it online from the same store's website or from a competitor's website. In this paper, we develop economic models of price competition between a traditional retailer and an online retailer under customer showrooming behaviour. Our results indicate that showrooming hurts the traditional retailer and benefits the online retailer in terms of sales volumes and profits. The combined offline and online market expands under showrooming. We consider two strategies-effort/investment made and online entry by the traditional retailer-to counter showrooming. Either strategy makes the traditional retailer better off, and the online retailer worse off, in terms of sales volumes and profits; also, the overall market, including offline and online sales, contracts. Moreover, when the traditional retailer makes an online entry, although its offline sales decrease, its total offline and online sales increase; also, although the overall market contracts, total online sales and the online price increase. We consider two scenarios of simultaneous and sequential moves made by the retailers to set their prices. We observe that both the retailers benefit under sequential moves than in the simultaneous move; however, the overall market demand is lower in
\end{abstract}

\section{S. Mitra $(\bowtie)$}

Indian Institute of Management Calcutta, Diamond

Harbour Road, Joka, Kolkata 700104, India

e-mail: subrata@iimcal.ac.in sequential moves than in the simultaneous move. We have also conducted sensitivity analyses to check for robustness of the results. We conclude the paper by highlighting the managerial implications of this research and providing possible directions for future research.

Keywords Retailing - Showrooming · Pricing · Economic models

\section{Introduction}

Showrooming is the phenomenon when a customer visits a traditional or brick-and-mortar retail store to view and experience a product, but instead of buying the product from the store, she buys it online from the same store's website or from a competitor's website. When customers search offline at a retail store, but buy online from a competitor's website (competitive showrooming), this adversely impacts the store's profitability. On the other hand, when customers search offline at a retail store, and buy online from the same store's website (loyal showrooming), this has a positive impact on the store's profitability (Frasquet and Miquel-Romero 2021; Rajkumar et al. 2021). Zhang et al. (2021) define competitive showrooming as intra-showrooming and loyal showrooming as intershowrooming. It is as if the physical store acts as a showroom for the online sales channel. The term 
'showrooming' became popular when there were talks in the US media that the electronics chain Best Buy had become a 'showroom for Amazon' (Goodfellow 2012; Quint et al. 2013). Traditional retailers ${ }^{1}$ consider showrooming a serious threat to their sales potential. The growing availability of smartphones and easy accessibility of the internet have further fuelled customer showrooming behaviour and added to the concern of traditional retailers. Surveys have shown that showrooming can vary from about $40 \%$ to $60 \%$ and can be as high as $70 \%$ if only shoppers using smartphones in-store are taken into consideration (Zimmerman 2012; Quint et al. 2013; Balakrishnan et al. 2014; Rapp et al. 2015; Gensler et al. 2017; Rejon-Guardia and Luna-Nevarez 2017; Kuksov and Liao 2018; Fassnacht et al. 2019; Flavian et al. 2020; Chai et al. 2021; Frasquet and Miquel-Romero 2021; Johnson and Ramirez 2021; Zhang et al. 2020; Zhang et al. 2021). A PwC report revealed that $68 \%$ of consumers gathered product information at offline stores before purchasing online (Rajkumar et al. 2021). Research shows that for certain product categories, such as electronics and appliances, $83 \%$ of shoppers practice showrooming (Teixeira and Gupta 2015). Shoppers, who use smartphones, look for price comparison, product information and customer review on the websites and apps of traditional and online retailers before making a purchasing decision. Products such as electronics, appliances, sporting goods, clothing/apparel, shoes, books and furniture, which are 'non-digital' in nature (Balakrishnan et al. 2014; Bell et al. 2014; Mehra et al. 2018; Li et al. 2021; Rajkumar et al. 2021) and for which shoppers value instore view-touch-feel-and-fit experience, are more prone to showrooming than other types of products that are generic in nature such as groceries (Quint et al. 2013; Rejon-Guardia and Luna-Nevarez 2017; Jing 2018).

The primary reasons for showrooming cited by shoppers, who engage in showrooming, are lower online prices [Amazon's prices for consumer electronics were $11 \%$ and $8 \%$ lower than Walmart's and Best Buy's in-store prices, respectively; also, Amazon's prices were $14 \%$ below Target's prices (Zimmerman 2012)], a desire to experience the product at a physical store before purchasing it online, shopping

\footnotetext{
${ }^{1}$ Traditional retailers sell through physical or brick-and-mortar retail stores.
}

and delivery convenience of online purchase, and product unavailability at physical stores (Quint et al. 2013; Teixeira and Watkins 2015; Rajkumar et al. 2021). Showrooming has pretty badly affected large traditional US retailers. Some of the scaring news items published in the literature are as follows. Walmart lost $\$ 20$ billion in market cap in one day (Mohammed 2015). Target's sales were flat. Sales at Best Buy stores opened in the previous year had fallen by more than $4 \%$. At Penney, same-store sales dropped by $26 \%$ compared to the same period the year before (Teixeira and Watkins 2015). Benjy's quarterly loss mounted to $\$ 700$ million (Teixeira and Gupta 2015). According to Retail Next, although traditional retailers still account for $94 \%$ of retail sales, footfall is declining at an annual rate of $15 \%$ and half of the customers are showrooming. ${ }^{2}$ Yet another report states that in the USA, 6000 traditional stores had to shut shop, resulting in a loss of 100,000 jobs, and one-third of shopping malls will either fail or have to reinvent themselves in the next 10 years (Darlington 2019). While the traditional retailers were experiencing a sharp decline in sales, the online retail market was growing at $17 \%$ per year (Teixeira and Watkins 2015). According to another estimate, online retail sales grew 23\% in 2015 while Amazon became the largest online retailer accounting for $26 \%$ of total online retail sales (Sopadjieva et al. 2017). Although the decline in sales at physical stores and growth of online retail cannot be entirely attributed to the phenomenon of showrooming, it is now evident that showrooming does play a significant role in weaning away shoppers from physical stores to the online marketplace.

This paper develops economic models of price competition between a traditional retailer and an online retailer under customer showrooming behaviour. Two scenarios have been considered for setting prices, namely when the retailers simultaneously set their prices, and when one of the retailers acts as the Stackelberg leader, and the other follower, to sequentially set their prices. Also, when the retailers simultaneously set their prices, the competitive dynamics in the presence of the traditional retailer's strategies, namely the effort/investment made by the traditional

\footnotetext{
${ }^{2}$ https://eds.b.ebscohost.com/eds/pdfviewer/pdfviewer?vid=0 \&sid=59059b64-e5df-4afe-beea-216a5da17d23\%40sessionm gr101, Last accessed on October 10, 2021.
} 
retailer and the traditional retailer's online entry, to counter showrooming are analysed. The extant literature shows contradictory results as to the benefits/ losses accrued to the traditional and online retailers in the presence of showrooming. The objective of this paper is to investigate the movement of prices, sales and profits of the two retailers under showrooming and also when the traditional retailer adopts the abovementioned strategies to counter showrooming under some practical assumptions made in the paper. It is intended to compare the assumptions and findings of the current paper with those in the extant literature and observe under what conditions the results corroborate or conflict with each other. In particular, the following questions have been addressed in this paper:

(a) Does showrooming benefit, or hurt, the traditional and online retailers?

(b) Does showrooming increase, or decrease, the overall market demand?

(c) How do the strategies adopted by the traditional retailer to counter showrooming alter the competitive dynamics and affect the overall market demand?

(d) How do the simultaneous and sequential moves by the retailers to set prices compare in terms of prices, sales volumes and profits of the retailers and the overall market demand?

The significant findings of this paper are as follows: When the retailers simultaneously set their prices,

(a) Prices, sales and profits decrease for the traditional retailer and increase for the online retailer under showrooming.

(b) The combined offline and online demand increases with showrooming, indicating customer benefits due to showrooming.

(c) When the traditional retailer puts in effort/makes an investment to counter showrooming, the price, sales and profit of the traditional retailer increase while the same decrease for the online retailer. Also, the combined offline and online demand decreases, hurting customers in the process.

(d) When the traditional retailer makes an online entry to counter showrooming, its price and profit increase. As far as the sales volume is concerned, the traditional retailer's offline sales volume decreases; however, its total sales volume, including offline and online sales, increases. On the other hand, for the online retailer, while the price increases, its sales volume and profit decrease. From the customers' point of view, while online sales, including the sales of the online arm of the traditional retailer and the online retailer, increase, total offline and online sales decrease. This result points to the fact that upon online entry by the traditional retailer, although the online market expands, the overall market, including offline and online, contracts.

When the retailers sequentially set their prices, in comparison with when the retailers simultaneously set their prices,

(a) Irrespective of which retailer acts as the leader, prices and profits of both the retailers increase. However, the price charged by a retailer is the highest when it acts as the leader while the profit made by a retailer is the highest when it acts as a follower.

(b) When the traditional retailer acts as the leader, offline sales decrease and online sales increase.

(c) When the online retailer acts as the leader, offline sales increase and online sales decrease.

(d) Irrespective of which retailer acts as the leader, total offline and online sales decrease, and the combined sales volume is the lowest when the traditional retailer acts as the leader.

Almost all the proofs (except one) in this paper are parameter-independent, i.e. they hold for the entire ranges of parameter values and not for specific ranges, thereby making the findings of this paper robust.

The rest of the paper is organized as follows. "Literature review" Section presents the literature review. "Problem description and modelling assumptions" Section describes the problem and modelling assumptions. "Model development" Section presents the economic models. In "Demand and profit functions for the retailers" Section, the demand and profit functions for the retailers are explained. "Simultaneous move by the retailers to set prices" Section presents the economic model of price competition between the traditional and online retailers under customer showrooming behaviour when the retailers simultaneously set their prices. Economic models for the effort/investment made and online entry by the 
traditional retailer to counter showrooming are derived in "Effort/investment made by the traditional retailer to counter showrooming and Online entry by the traditional retailer to counter showrooming" Sections, respectively. "Sequential move by the retailers to set prices" Section presents the economic models when the retailers sequentially set their prices. Models when the traditional retailer acts as the leader and when the online retailer acts as the leader are derived in "Traditional retailer as the leader and online retailer as the follower and Online retailer as the leader and traditional retailer as the follower" Sections, respectively. "Summary of results and managerial implications" Sections presents a summary of results and highlights the managerial implications of this research. Finally, "Conclusions, limitations of the study and directions for future research" Section presents concluding remarks and directions for future research.

\section{Literature review}

The extant literature is rich in multichannel competition in retail. In multichannel retail, the literature is replete with the competitive dynamics between a manufacturer and a traditional retailer when the manufacturer decides to sell directly through an online sales channel besides selling through the brick-andmortar retail store (see, for example, Tsay and Agrawal 2004; Cattani et al. 2006; Wang et al. 2018; Feng et al. 2019). There is also a vast amount of literature on click-and-mortar, i.e. when a traditional retailer creates an online channel and sells both offline and online (see, for example, Ofek et al. 2011; Zhang et al. 2017; Radhi and Zhang 2019). Brynjolfsson and Smith (2000) and Li et al. (2015) study the dynamics among traditional retailers that sell through physical stores only, online retailers that sell online only and 'hybrid' retailers that sell both offline and online. Brynjolfsson et al. (2009) and Abhishek et al. (2016) analyse the competitive dynamics between traditional and online retailers. Agatz et al. (2008) present a literature review on the integration of e-fulfilment with multiple alternative distribution channels or bricksand-clicks.

None of the above papers considers showrooming in multichannel retail. There is, of course, literature on free riding where customers free-ride information on one channel and buy on another channel. Wu et al. (2004) study the free-riding phenomenon among two groups of online retailers where one group of retailers provides informational services while the other group does not. Customers may free-ride information provided by the former group of retailers and buy at a lower price from the latter group of retailers. The authors find that an online retailer has to provide informational services to make positive profits even if there is free riding and retailers cannot make positive profits by free riding all the time. Shin (2007) in the context of two traditional retailers-one serviceproviding and the other free riding-shows that freeriding benefits not only the free-riding retailer, but also the retailer that provides service. Free riding not only reduces the intensity of price competition, but also enables the service-providing retailer to charge a higher price and make positive profits.

Xing and Liu (2012) consider a manufacturer selling through a traditional and an online retailer. The online retailer free-rides the sales effort put up by the traditional retailer which reduces the effort of the traditional retailer, thereby affecting the manufacturer's profit and overall supply chain performance. The authors discuss the role of various contracts in coordinating the sales effort of the traditional retailer and improving the supply chain efficiency. Zhou et al. (2018) consider a manufacturer selling through a direct online sales channel and a traditional retailer. The manufacturer's online sales channel free-rides the pre-sales informational services provided by the traditional retailer by sharing its cost of service. The authors investigate how free riding affects the pricing/ service strategies and profits of the dual channels.

Showrooming, as defined earlier, is a special kind of service free riding in retail (Gensler et al. 2017; Jing 2018; Viejo-Fernandez et al. 2020; Chai et al. 2021; Li et al. 2021). Rajkumar et al. (2021) define showrooming as a cross-channel free-riding behaviour that involves offline search followed by online purchase. According to Balakrishnan et al. (2014), showrooming intensifies competition between a traditional and an online retailer, reducing profits for both the firms. Basak et al. (2017) also observe that profits for both the retailers decrease as showrooming increases. Therefore, reduced showrooming is not only beneficial for the traditional retailer, but also desirable from the point of view of the online retailer. However, a 
high level of showrooming benefits customers by reducing retail prices.

Mehra et al. (2018) consider competition between a traditional retailer and an online retailer under showrooming. They show that showrooming is detrimental to the profit of the traditional retailer. They analyse two strategies for the traditional retailer to counter showrooming, namely price matching and exclusivity of product assortment through arrangements with known brands and creation of store brands. While price matching is proposed to be a short-term strategy, exclusivity of product assortment is considered to be a long-term strategy. The authors show that price matching is more effective under showrooming than when there is no showrooming, and implementing product exclusivity through the store-brand strategy is better than exclusivity through the known-brand strategy under showrooming while the opposite is true when there is no showrooming. Kuksov and Liao (2018) consider the role of contracts between a manufacturer and a traditional retailer and show that the traditional retailer's profit may actually increase under showrooming. The authors state that the overall demand increases under showrooming and hence the manufacturer may incentivize the traditional retailer for providing informational services either through a lower wholesale price or through direct compensation. Manufacturer incentives may, therefore, increase the traditional retailer's profit even if it invests in improving the store service level. The authors have developed their model under some strong assumptions such as a single manufacturer has been considered who is selling both offline and online and hence interbrand competition has been ignored; all shoppers, irrespective of whether they would ultimately buy from a physical store or online, visit the physical store which may not be true in practice, and some shoppers would never visit the physical store and always buy online; and shoppers' valuation of products online is lower than that in a physical store which, again, may not be always true, especially for 'non-digital' products. The authors do, of course, admit that their model also shows the possibility that showrooming could be detrimental to the traditional retailer's profit.

Jing (2018) considers competition between a traditional and an online retailer in the presence of showrooming. The author shows that under low product match uncertainty, showrooming intensifies competition and decreases the profits of both the retailers, thus supporting the retailers' recent strategy to stock more exclusive products. However, the author concludes that under high product match uncertainty, showrooming may have different effects on competition and may very likely increase the online retailer's profit. Zhang and Zhang (2020) consider offline entry by a supplier that sells through an online channel. Their study focuses on the online retailer's demand information sharing strategy with the supplier under the agency selling and reselling agreements. The authors observe that the online retailer may be better off with supplier offline entry when there is showrooming and is always worse off when there is no showrooming. When the supplier makes an offline entry, showrooming enables customers to get information offline and buy online which may bring additional online revenues and benefit the online retailer. For a low level of showrooming, the loss from channel competition due to supplier offline entry dominates the benefits of showrooming and hence it hurts the online retailer while for a high level of showrooming, the benefits of showrooming outweigh the loss from channel competition and the online retailer benefits by supplier offline entry.

Li et al. (2019) consider a dual-channel supply chain where a manufacturer sells directly through an online sales channel and indirectly through a traditional retailer. The authors study the effect of showrooming on the wholesale and retail prices and channel profitability under three service strategies of the traditional retailer-no service, ex ante and ex post. In the no-service strategy, the traditional retailer does not exert any service effort and hence the showrooming effect is non-existent. This situation serves the purpose of the benchmark model. In the ex ante service strategy, the traditional retailer sets the level of its service effort before the manufacturer decides its wholesale and online retail prices. On the other hand, in the ex post service strategy, the traditional retailer sets the level of its service effort and retail price after the manufacturer has decided its wholesale and online retail prices. The authors show that the firms are benefited the most by showrooming when the traditional retailer adopts the ex post service strategy. The showrooming effect results in the manufacturer charging a high wholesale price for the traditional retailer's ex ante service strategy and a low wholesale price for the latter's ex post service strategy. Moreover, the study shows that as the showrooming effect 
increases, the firms reap higher profits when the traditional retailer adopts the ex post service strategy. The authors demonstrate the applicability of their models through three case studies on companies in the business of smart projectors, film industry and electrical appliances.

Basak et al. (2020) extend their earlier model (Basak et al. 2017) to analyse the effect of the wholesale price set by the manufacturer on the offline and online retail prices in the presence of showrooming. The authors investigate the feasibility of a coordination mechanism between the manufacturer and the traditional retailer so that the traditional retailer expends more sales effort to boost demand and create a dedicated customer base. The authors derive a three-parameter contract that can result in a winwin situation for the manufacturer and the traditional retailer, with more benefits for the traditional retailer with a relatively lower market potential. Moreover, the authors find that the contract brings down the retail price benefitting the customer.

Liu et al. (2020) study the impact of showrooming on an integrated dual channel, i.e. a retailer having both offline and online sales channels with joint pricing decisions for the channels and an associated return policy, and show that an appropriately designed dual channel can indeed increase the profitability of the retailer. The authors show that the retailer can intentionally create a channel price gap to encourage showrooming, which will result in considerable fulfilment and return cost savings. Moreover, the authors find that the return policy decisions are closely related to pricing decisions, and show that it may be beneficial for the retailer to engage with customers indirectly, rather than directly, via customer showrooming behaviour.

Raj et al. (2020) examine the effect of the unilateral pricing policy (UPP), in which the manufacturer sets a minimum retail price for both the traditional and online retailers to help the traditional retailer set a high level of pre-sales services for customers, on customer showrooming behaviour. The authors find that the UPP price depends on the extent of showrooming, customer price sensitivity and customer valuation of pre-sales services. The authors compare the outcomes of a UPP with those of a conventional pricing policy (CPP) where retailers set their prices independently.

Zhang et al. (2020) consider competition between two manufacturers that sell their products through an omnichannel retailer. The retailer showcases the product of one of the manufacturers at its physical store and sells the products of both the manufacturers through an online store. Customers can either buy products directly from the online store or inspect products at the physical store and then buy from the online store (showrooming). Two types of showrooming behaviour have been analysed-intra-showrooming and inter-showrooming. In intra-showrooming, customers inspect products displayed at the physical store and buy the same manufacturer's products from the online store. On the other hand, in inter-showrooming, customers inspect products of one manufacturer at the physical store, but buy products of the other manufacturer from the online store. The authors investigate the roles of customer inter-showrooming behaviour and information services provided by the physical store in an omnichannel environment. The authors find that customer inter-showrooming behaviour benefits the manufacturer whose products are not displayed at the physical store and sold online only and hurts the dual-channel manufacturer whose products are displayed at the physical store. Also, intershowrooming is beneficial to the omnichannel retailer when the inter-showrooming intensity is not too high. The authors study a coordination mechanism between the dual-channel manufacturer and the retailer to enhance information services provided at the physical store and find that the online-only manufacturer may be either better off or worse off depending on two counteracting effects of enhanced information services. Further, customers located away from the physical store are adversely affected by inter-showrooming and service compensation while local customers benefit from them. Finally, the authors note that in-store fulfilment, besides serving as a showroom, at the physical store will have a positive impact on the omnichannel retailer's information service provision.

Li et al. (2020) study the effect of opening a showroom by an online retailer on its profitability. The authors find that the feasibility of opening a showroom in terms of cost and availability of local customers increases the retailer's profit. The authors also find that the effect of different in-store assortment strategies on the retailer's profitability depends on the intensity of customer intra- and inter-showrooming behaviour, as defined above. Moreover, the expected return cost for pure online shopping is a critical determinant of the 
retailer's omnichannel pricing strategies and information service decisions.

Chai et al. (2021) use the Hotelling model to analyse the store brand strategy of a traditional retailer as a tool to mitigate the adverse impact of showrooming. The authors find that introducing premium store brands is an effective means to combat showrooming. As the breadth and depth of national brand product mismatch increase, the store brand strategy increases the profit of the traditional retailer and decreases the profit of the online retailer. However, an increase in store brand awareness would not necessarily increase the traditional retailer's profit; rather it would depend on the hassle cost and a brand promotion strategy would decrease the loss of the traditional retailer's profit.

Li et al. (2021) study the effect of showrooming in a dual-channel supply chain comprising a manufacturer, which operates a direct sales channel, and an online channel. The product in question has both digital and non-digital attributes. While customers can check both the digital and non-digital attributes at the physical store, they can check only the digital attributes at the online store. The authors investigate the impact of instore product demonstration on online and offline retail pricing decisions under customer showrooming behaviour. They observe that the showrooming behaviour may be beneficial to the manufacturer operating a physical store and harmful to the online retailer. Specifically, the authors find that when the level of in-store demonstration is medium, the manufacturer and the online retailer would be better off if they choose the non-demonstration and non-showrooming strategies, respectively. The authors also show that when the manufacturer sets the wholesale prices endogenously, both the manufacturer and the online retailer choose the same strategy, leading to Pareto improvement in the supply chain.

Zhang et al. (2021) explore the effect of intra- and inter-showrooming on a supplier and a traditional retailer when the supplier opens a direct online sales channel besides traditional retailing and the traditional retailer opens an online sales channel for omnichannel retailing. The authors show that showrooming can benefit both the supplier and the traditional retailer when customers' hassle costs for visiting the physical store and the traditional retailer's additional revenue for each customer visit are medium. Further, the authors show that the traditional retailer's omnichannel strategy may shrink this 'win-win' range because of the aggravating competition effect of showrooming.

For a systematic literature review on webrooming, showrooming and omnichannel retailing, readers may refer to Sahu et al. (2021).

The literature review reveals that the effect of showrooming on traditional and online retailing has been studied from various perspectives. For example, the problem set-ups and assumptions have been different for different papers. While some of the papers have focused on the effect of showrooming on the competition between traditional and online retailers (e.g. Balakrishnan et al. 2014; Basak et al. 2017; Jing 2018; Mehra et al. 2018; Chai et al. 2021) or on a traditional retailer opening an online sales channel and vice versa (e.g. Li et al. 2020; Liu et al. 2020; Zhang and Zhang 2020; Zhang et al. 2021), others have studied the effect of showrooming on a dual-channel supply chain, i.e. a manufacturer supplying to two competing traditional and online retailers (e.g. Basak et al. 2020; Raj et al. 2020), a manufacturer selling directly through an online sales channel and indirectly through a traditional retailer (e.g. Kuksov and Liao 2018; Li et al. 2019), a manufacturer selling directly through a physical store and indirectly through an online retailer (e.g. Li et al. 2021) or two competing manufacturers with one selling only through an online sales channel and the other selling through both a traditional retailer and an online sales channel (e.g. Zhang et al. 2020). While some papers have explicitly considered travelling/hassle/(in)convenience costs in connection with purchasing on a particular channel (e.g. Balakrishnan et al. 2014; Mehra et al. 2018; Li et al. 2020, 2021; Liu et al. 2020; Chai et al. 2021; Zhang et al. 2021), others have ignored such costs (e.g. Basak et al. 2017, 2020; Li et al. 2019; Raj et al. 2020). Also, the economic models used to analyse the effect of showrooming have been different in different papers. While one set of papers have used linear demand functions with sales/service/advertising efforts of the traditional retailer, the other set of papers have derived demand functions based on the utility theory to model customer showrooming behaviour. Most of the papers have developed game theoretic models either with simultaneous moves or with one of the players as the Stackelberg leader and others as followers to set their respective prices and sales/service effort levels. Therefore, the results 
derived by these papers have also been different. While some of the papers conclude that showrooming benefits the online retailer and adversely affects the traditional retailer (e.g. Mehra et al. 2018), others reveal that showrooming has a negative impact on both the traditional and online retailers (e.g. Balakrishnan et al. 2014; Basak et al. 2017; Jing 2018). Also, that showrooming may increase the traditional retailer's profit has been observed by some authors (e.g. Kuksov and Liao 2018; Zhang et al. 2021). Similarly, for a dual-channel supply chain, the effect of showrooming on the profitability of the manufacturer(s) and the retailers, and also of the supply chain as a whole, has been studied for various scenarios. Strategies that the manufacturer and the traditional retailer may adopt, such as price matching, exclusivity of product assortment at the physical store (e.g. Jing 2018; Mehra et al. 2018; Li et al. 2020; Chai et al. 2021), opening an online sales channel and/or increasing sales/service efforts (e.g. Basak et al. 2017, 2020; Li et al. 2019, 2021; Raj et al. 2020; Zhang and Zhang 2020), to combat showrooming have also been studied in detail in the literature. Although the results might have been different for different problem set-ups and modelling assumptions, the literature is unanimous about the importance of studying the impact of customer showrooming behaviour on retailing and the strategies that manufacturers and traditional retailers may adopt to mitigate the ill effects of showrooming and how the same can be exploited to their advantage, making this evolving area contemporary and worthwhile for research.

\section{Problem description and modelling assumptions}

We consider price competition between a traditional and an online retailer, who sell an identical product, under customer showrooming behaviour. First, we develop economic models when the retailers simultaneously decide on their prices, in line with Balakrishnan et al. (2014) and Mehra et al. (2018). We assume that the selling period is short and the retailers simultaneously announce their prices based on the best response function of the other retailer. Next we consider two strategies-effort/investment made and online entry by the traditional retailer-to counter showrooming and extend the economic models. Finally, we develop economic models for the scenario when one of the retailers acts as the Stackelberg leader, and the other follower, to sequentially set their prices, in line with Basak et al. (2017). The sequential decision-making process is relevant when the selling period is sufficiently long and one of the retailers is dominant and more powerful than the other retailer. In this scenario, the leader first sets its price based on the best response function of the follower and then the follower sets its price by observing the price set by the leader. The following are the practical assumptions made in the models and their justifications:

(a) The market potential of the traditional retailer is greater than that of the online retailer. Although online retail sales are growing faster than offline retail sales, according to the latest US Census Bureau report, online retail sales are still about $11.8 \%$ of total retail sales in the first quarter of 2020 in the US Census Bureau News (2020). Even when we consider different categories of products, some of them are experiencing faster growth rates in online sales than other categories; however, their online sales are still far below their offline sales. According to a report (Statista 2020), books, movies, music, games, apparel, shoes, consumer electronics, cosmetics and body care, and bags and accessories show high potential for online sales, but less than $40 \%$ of the respondents in the USA, who participated in the survey, would buy or order these items online while the rest would still prefer to buy them offline. Another report (Wilson 2017) mentions that even though online grocery purchases show an increasing trend, 93\% of shoppers still prefer to inspect the produce instore; also, for apparel and fast fashion and sporting goods, although their online sales are increasing in volume, more than $75 \%$ and $50 \%$ of consumers, respectively, still prefer to buy them in-store. Yet another report (Kesteloo and Hoogenberg 2013) predicts that the share of online sales in four categories-health and beauty, consumer electronics and appliances, toys and games, and apparel-will increase from 9 to $27 \%$ by 2020 in the Netherlands. From the data presented, it is clear that offline sales will dominate online sales for almost all, if not all, product categories in the foreseeable future. Therefore, models developed in this paper 
ensure that the traditional retailer's offline sales volume always exceeds the online retailer's sales volume. This is in contrast to the assumptions made by Basak et al. $(2017 ; 2020)$ and Zhou et al. (2018), who either have allowed the market potential of the online retailer to exceed that of the traditional retailer or have considered equal market potential for offline and online sales.

(b) Shoppers, who buy from traditional stores, and shoppers, who showroom, are not homogenous although they buy identical products in-store and online, respectively. Shi et al. (2019) also note customer heterogeneity in online vs. offline retail competition. As mentioned earlier, one of the primary reasons for shopping online is that online retail prices are generally lower than offline retail prices for most of the products, and the showrooming phenomenon bears testimony to this fact wherein price-sensitive shoppers check products in traditional stores, but prefer to buy online because of lower prices. A survey conducted by Quint et al. (2013) shows that the top three reasons for showrooming are 'lower price from the online retailer', 'free shipping from the online retailer' and 'always planning to purchase the product online' with 69,47 and $27 \%$ of the respondents citing the reasons, respectively. Gensler et al. (2017) also observe that expected average price savings from showrooming are positively associated with showrooming. Balakrishnan et al. (2014) and Mehra et al. (2018) note that showroomers visit a traditional store to experience a product and then switch to an online retailer to buy it at a cheaper price. All these evidences point to the fact that shoppers, who showroom, are more price-sensitive than shoppers, who buy from traditional stores. Showroomers are fundamentally online shoppers, who visit traditional stores for experience and information, but instead of buying in-store, they buy online at a price lower than that in traditional stores. In general, pricing has been found to be one of the major drivers of online purchase decisions for most of the product categories (KPMG 2017). Therefore, we assume that the own- and crossprice sensitivities of online demand are greater than the respective own- and cross-price sensitivities of offline demand, which leads to the offline retail price being greater than the online retail price in the models developed in this paper. This is, again, in contrast to the assumptions made by Basak et al. (2017, 2020), Zhou et al. (2018), Li et al. (2019) and Raj et al. (2020), who consider the same own- and crossprice sensitivities of the offline and online demand.

(c) We consider a downward-sloping linear demand function where the constant (or intercept) represents factors, other than price, that contribute to demand. Therefore, the constant term in the demand function, ceteris paribus, represents the market potential of a product given that its price approaches zero. We assume that the non-price factors associated with customer showrooming behaviour, such as convenience, flexibility, free shipping and home delivery, contribute to the market potential of demand. Therefore, showrooming will induce a reduction in the market potential of offline demand and an increase in the market potential of online demand of equal magnitude. This is contrary to the assumption made by Basak et al. (2017, 2020), Li et al. (2019) and Zhang and Zhang (2020), who define the shift in demand as a function of sales/service effort put in by the traditional retailer. However, their assumption does not take into consideration the fact that showrooming is a behavioural phenomenon that is influenced by internal and external factors such as demographics, previous showrooming experience, social pressure and accepted social norm, availability of smartphones and other mobile devices, accessibility to high-speed internet and a continued upsurge of internet retailers, besides price consciousness (RejonGuardia and Luna-Nevarez 2017; Dahana et al. 2018; Sit et al. 2018). There is no empirical evidence that increasing sales effort by the traditional retailer will increase the demand faced by the online retailer due to showrooming. On the contrary, the extant literature highlights increasing sales effort by the traditional retailer as a strategy to counter showrooming. Therefore, in this paper, we have modelled customer showrooming behaviour as an exogenous 
parameter that affects the market potential of either retailer.

\section{Model development}

In this section, first the notations used in model development are listed. Then, the demand and profit functions for the traditional and online retailers are explained. Next, a game-theoretic model of the system when the retailers simultaneously decide on their respective prices under showrooming is derived, followed by model development for the effort/investment made by the traditional retailer to counter showrooming.

Notations:

Index

$i \quad\{1$ : Traditional retailer; 2: Online retailer $\}$

Parameters

$\alpha \quad$ Market potential of online sales as a fraction of the market potential of offline sales

$\beta, \gamma, \theta \quad$ Parameters representing sensitivity of demand functions to prices

$s \quad$ Parameter representing the showrooming behaviour of customers as a fraction of the market potential of offline sales

Variables

$p_{1}\left(p_{2}\right) \quad$ Price charged by the traditional (online) retailer

$q_{1}\left(q_{2}\right) \quad$ Demand/sales volume for the traditional (online) retailer

$\Pi_{l}\left(\Pi_{2}\right) \quad$ Profit of the traditional (online) retailer

Demand and profit functions for the retailers

The normalized demand functions for the traditional and online retailers can be written as follows:

$$
\begin{aligned}
& q_{1}=(1-s)-p_{1}+\beta \theta p_{2} \\
& q_{2}=(\alpha+s)-\theta p_{2}+\gamma p_{1}
\end{aligned}
$$

We consider linear demand functions in line with Basak et al. (2017, 2020), Zhou et al. (2018), Li et al. (2019), Raj et al. (2020) and Zhang and Zhang (2020). We assume that the showrooming behaviour of customers affects the market potential of offline and online sales. Accordingly, the expressions for market potential in the demand functions reflect the showrooming effect. Here, $\alpha, \beta$ and $\gamma$ are parameters such that $0<\alpha, \beta, \gamma<1$. Since it is assumed that online customers are more price-sensitive than offline customers, it follows $\theta>1$. Since it is also assumed that online customers are more likely to switch to offline purchase in case of an increase in online price than offline customers, who prefer to shop at traditional stores and may not be as tech-savvy as online customers to make a move to online stores when the offline price increases, it follows $\beta>\gamma$. According to the assumption that the market potential of online sales is lower than the market potential of offline sales, it follows $\alpha+s<1-s$ or $s<\frac{1-\alpha}{2}$.

Therefore, assuming that the variable cost is the same for online and offline sales and normalizing it to zero, the profit functions for the traditional and online retailers can be written as follows:

$$
\begin{aligned}
& \Pi_{1}=p_{1} q_{1}=p_{1}\left[(1-s)-p_{1}+\beta \theta p_{2}\right] \\
& \Pi_{2}=p_{2} q_{2}=p_{2}\left[(\alpha+s)-\theta p_{2}+\gamma p_{1}\right]
\end{aligned}
$$

Simultaneous move by the retailers to set prices

This is considered as the base case. Here, the traditional and online retailers move simultaneously to decide on their respective prices not knowing what the pricing strategy of the other retailer would be. Assuming that both the retailers are rational, they settle for Nash equilibrium prices, as commonly found in the literature.

Therefore, to obtain Nash equilibrium prices, we partially differentiate the profit functions, Eqs. (1) and (2), with respect to their corresponding prices and equate them to zero. Subsequently, by solving the two equations, we obtain the following Nash equilibrium prices:

$$
\begin{aligned}
& p_{1}=\frac{\beta(\alpha+s)+2(1-s)}{4-\beta \gamma} \\
& p_{2}=\frac{2(\alpha+s)+\gamma(1-s)}{\theta(4-\beta \gamma)}
\end{aligned}
$$

The expressions for Nash equilibrium $q_{1}, q_{2}, \Pi_{1}$ and $\Pi_{2}$ are obtained as follows: 


$$
\begin{aligned}
q_{1}= & (1-s)-p_{1}+\beta \theta p_{2}=(1-s) \\
& -\frac{\beta(\alpha+s)+2(1-s)}{4-\beta \gamma}+\frac{\beta[2(\alpha+s)+\gamma(1-s)]}{4-\beta \gamma} \\
= & \frac{\beta(\alpha+s)+2(1-s)}{4-\beta \gamma}=p_{1}
\end{aligned}
$$

$$
\begin{aligned}
q_{2}= & (\alpha+s)-\theta p_{2}+\gamma p_{1}=(\alpha+s) \\
& -\frac{2(\alpha+s)+\gamma(1-s)}{4-\beta \gamma}+\frac{\gamma[\beta(\alpha+s)+2(1-s)]}{4-\beta \gamma} \\
= & \frac{2(\alpha+s)+\gamma(1-s)}{4-\beta \gamma}=\theta p_{2}
\end{aligned}
$$

$\Pi_{1}=p_{1} q_{1}=\frac{[\beta(\alpha+s)+2(1-s)]^{2}}{(4-\beta \gamma)^{2}}$

$\Pi_{2}=p_{2} q_{2}=\frac{[2(\alpha+s)+\gamma(1-s)]^{2}}{\theta(4-\beta \gamma)^{2}}$

Table 1 shows the optimal prices, sales and profits of the traditional and online retailers for the base case.

Proposition 1 The following will hold under showrooming:
(a) $p_{1}>p_{2}$
(b) $q_{1}>q_{2}$
(c) $\Pi_{1}>\Pi_{2}$

Proofs of all propositions are given in Appendix 1.

Proposition (1) shows that the price, sales volume and profit of the traditional retailer are higher than those for the online retailer under showrooming. It can be shown that the same would have held even if there

Table 1 Optimal prices, sales and profits of the traditional and online retailers (base case)

\begin{tabular}{lll}
\hline & Traditional retailer & Online retailer \\
\hline Optimal price & $\frac{\beta(\alpha+s)+2(1-s)}{4-\beta \gamma}$ & $\frac{2(\alpha+s)+\gamma(1-s)}{\theta(4-\beta \gamma)}$ \\
Optimal sales & & \\
& $\frac{\beta(\alpha+s)+2(1-s)}{4-\beta \gamma}$ & $\frac{2(\alpha+s)+\gamma(1-s)}{4-\beta \gamma}$ \\
Optimal profit & $\frac{[\beta(\alpha+s)+2(1-s)]^{2}}{(4-\beta \gamma)^{2}}$ & $\frac{[2(\alpha+s)+\gamma(1-s)]^{2}}{\theta(4-\beta \gamma)^{2}}$ \\
\hline
\end{tabular}

was no showrooming. This is especially true under the assumption that the market potential of offline sales is higher than that of online sales and online customers are more price-sensitive than offline customers. Results may vary under a different setting in Basak et al. (2017) and Zhou et al. (2018), who consider that the market potential of online sales can exceed that of offline sales or they may be equal, and offline and online customers are equally price-sensitive.

Further, it can be easily shown from Eqs. (3-8) that the Nash equilibrium prices, sales volumes and profits of both the retailers assume fractional values under normalized demand functions.

We have performed a sensitivity analysis of the traditional and online retailers' profits against the parameters $\alpha, \theta$ and $s$. The results of the sensitivity analysis are presented in Appendix 2. Figure 1 shows that both retailers' profits increase with $\alpha$; however, the online retailer's profit increases at a faster rate than that of the traditional retailer, thereby making the difference in the traditional and online retailers' profits a decreasing function of $\alpha$. It is observed that this difference is positive as long as the market potential of the online retailer is lower than that of the traditional retailer; however, when the market potential of the online retailer crosses the same for the traditional retailer, the online retailer realizes a higher profit than the traditional retailer. Figure 2 plots the traditional and online retailers' profits against $\theta$. When $\theta$ increases, the traditional retailer's profit remains unchanged since it is not dependent on $\theta$, but the online retailer's profit decreases. Therefore, the difference in the traditional and online retailers' profits increases with $\theta$. The result is intuitive since $\theta$ represents the price-sensitivity of online customers and we have assumed that the same is at least equal to the price-sensitivity of offline customers. Figure 3 shows that the traditional retailer's profit decreases and the online retailer's profit increases with the showrooming parameter, $s$. Therefore, the difference in the retailers' profits decreases as $s$ increases with the difference being positive for small values of $s$ and negative for large values of $s$. It may be noted that as $s$ increases, the market potential of the online retailer increases and the same for the traditional retailer decreases. As observed in Fig. 1, when the market potential of the traditional retailer is higher than that of the online retailer, the traditional retailer realizes a higher profit than the online retailer; however, when 
the market potential of the online retailer crosses the same for the traditional retailer, the profit of the online retailer also exceeds the same for the traditional retailer. Therefore, the results of this paper are dependent on the assumptions made for model development.

Proposition $2 p_{1}, q_{1}$ and $\Pi_{1}$ decrease with $s$ for the traditional retailer, while $p_{2}, q_{2}$ and $\Pi_{2}$ increase with $s$ for the online retailer.

Proposition (2) shows that under increasing customer showrooming, the online retailer benefits at the expense of the traditional retailer, although the price, sales volume and profit of the traditional retailer are always higher than those for the online retailer. This is in line with the finding of Xing and Liu (2012), who observe that the profit of the traditional retailer is affected when the online retailer free-rides information on the traditional sales channel. Proposition (2) also supports the findings of Kuksov and Liao (2018) and Mehra et al. (2018), who show that showrooming could be detrimental to the profit of the traditional retailer. However, this is in contrast to the observation made by Shin (2007), i.e. both the service-providing and the free-riding retailers benefit as a result of customer free-riding information on one channel and buying on another channel. On the other hand, Balakrishnan et al. (2014), Basak et al. (2017) and Jing (2018) show that showrooming intensifies competition between the traditional and online retailers, reducing profits for both the firms. Therefore, reduced showrooming is beneficial from the point of view of both the traditional and online retailers. On the contrary, Proposition (2) indicates that while the online retailer benefits as a result of customer freeriding information on the traditional channel (showrooming) and buying on the online channel, the traditional retailer, which provides informational services, is adversely impacted in terms of its price, sales volume and profit. As mentioned, this result will hold as long as the market potential of offline sales is higher than that of online sales and online customers are more price-sensitive than offline customers. Figure 3 in Appendix 2 presents a sensitivity analysis of the retailers' profits against the showrooming parameter, $s$.
Proposition 3 The combined offline and online demand, $q_{1}+q_{2}$ increases with s.

Proposition (3) shows that although the traditional retailer loses market share, the gain in the market share of the online retailer results in an overall increase in demand under customer showrooming behaviour. This result indicates market expansion and customer benefits under showrooming and is in line with the observation made by Bell et al. (2018) and Kuksov and Liao (2018). The traditional retailer may lose market share to the online retailer under showrooming in the short run; however, an overall expansion of the market provides an opportunity to the traditional retailer to grab a pie of the expanded market in the long run. Also, the traditional retailer may expect lower wholesale prices and/or incentives from the manufacturer, who benefits from market expansion (Kuksov and Liao, 2018). It may be observed from the proof of Proposition (3) in Appendix 1 that the combined market demand also increases with parameters, $\alpha, \beta$ and $\gamma$, and it is independent of $\theta$.

Proposition 4 While prices, sales volumes and profits of both the retailers increase with the parameters, $\alpha, \beta$ and $\gamma$, the online retailer's price and profit decrease with the parameter, $\theta$.

Proposition (4) indicates that increasing market potential of the online channel and cross-price sensitivity parameters benefit both the retailers. In other words, if the market potential of the online channel increases at the same level of showrooming, it not only benefits the online retailer, but also increases the price, sales volume and profit of the traditional retailer. On the other hand, increasing own-price sensitivity parameter for the online retailer expectedly decreases its price and profit, while the traditional retailer remains unaffected. Figure 2 in Appendix 2 shows the sensitivity of the traditional and online retailers' profits against $\theta$.

Sensitivity analyses of the retailers' profits against the parameters $\beta$ and $\gamma$ are shown in Figs. 4 and 5 in Appendix 2, respectively. Figure 4 shows that while the traditional retailer's profit increases sharply with $\beta$, the online retailer's profit increases marginally with $\beta$, thereby making the difference in the retailers' profits sharply increase with $\beta$. On the other hand, Fig. 5 
shows that both the retailers' profits increase sharply with $\gamma$; however, the difference in their profits decreases as $\gamma$ increases. The sensitivity analyses reveal that both the retailers benefit by increasing cross-price sensitivities; however, their effects are different for the traditional and online retailers. It has been reasonably assumed that the cross-price sensitivity parameter, $\beta$ for the online retailer is at least equal to the cross-price sensitivity parameter, $\gamma$ for the traditional retailer.

Effort/investment made by the traditional retailer to counter showrooming

Suppose the traditional retailer puts in effort by way of rearranging the layout and display at the showroom to make it more attractive to customers, providing better in-store experiences, introducing loyalty/rewards programmes for customer retention, investing in technology such as mobile apps and in-store Wi-fi, investing in inventory so that items never go out of stock, and so on to mitigate customer showrooming behaviour. Let the normalized level of effort put in by the traditional retailer be represented by $\varepsilon$ such that $0<\varepsilon<1$. Also, let the associated normalized investment made by the traditional retailer be $\varepsilon^{2}$ such that the investment required increases quadratically with the level of effort. Although Basak et al. (2017, 2020) consider a linear cost function, we consider an increasing and convex cost function in line with Tsay and Agrawal (2004), Xing and Liu (2012), Kuksov and Liao (2018), Zhou et al. (2018), Li et al. (2019), Raj et al. (2020), and Zhang and Zhang (2020). It is assumed that with a level of effort of $\varepsilon$, the showrooming parameter, $s$, reduces to $s(1-\varepsilon)$, i.e. drops by $100 \times \varepsilon \%$ or, in other words, it may be said that $100 \times \varepsilon \%$ of sales that were lost to showrooming, may now be reclaimed, thus increasing the market potential of the traditional retailer by the same amount. Then, the normalized demand and profit functions for the retailers can be written as follows:

$$
\begin{aligned}
& q_{1}=\{1-s(1-\varepsilon)\}-p_{1}+\beta \theta p_{2} \\
& q_{2}=\{\alpha+s(1-\varepsilon)\}-\theta p_{2}+\gamma p_{1} \\
& \Pi_{1}=p_{1} q_{1}-\varepsilon^{2} \\
& =p_{1}\left[\{1-s(1-\varepsilon)\}-p_{1}+\beta \theta p_{2}\right]-\varepsilon^{2} \\
& \Pi_{2}=p_{2} q_{2}=p_{2}\left[\{\alpha+s(1-\varepsilon)\}-\theta p_{2}+\gamma p_{1}\right]
\end{aligned}
$$

It may be noted that for the traditional retailer, $\varepsilon$ is an additional variable in this model. Therefore, partially differentiating Eq. (10) with respect to $p_{1}$ and $\varepsilon$, partially differentiating Eq. (11) with respect to $p_{2}$, and equating them to zero, we get three equations. Solving these three equations, we get the following Nash equilibrium solutions:

$p_{1}=\frac{2[\beta(\alpha+s)+2(1-s)]}{2(4-\beta \gamma)-s^{2}(2-\beta)}$

$p_{2}=\frac{\left(4-s^{2}\right)(\alpha+s)+\left(2 \gamma-s^{2}\right)(1-s)}{\theta\left[2(4-\beta \gamma)-s^{2}(2-\beta)\right]}$

$\varepsilon=\frac{s[\beta(\alpha+s)+2(1-s)]}{2(4-\beta \gamma)-s^{2}(2-\beta)}$

The expressions for $q_{1}, q_{2}, \Pi_{1}$ and $\Pi_{2}$ are obtained as follows:

$$
\begin{aligned}
q_{1}= & 1-s\left[1-\frac{s\{\beta(\alpha+s)+2(1-s)\}}{2(4-\beta \gamma)-s^{2}(2-\beta)}\right] \\
- & \frac{2[\beta(\alpha+s)+2(1-s)]}{2(4-\beta \gamma)-s^{2}(2-\beta)} \\
+ & \frac{\beta\left[\left(4-s^{2}\right)(\alpha+s)+\left(2 \gamma-s^{2}\right)(1-s)\right]}{2(4-\beta \gamma)-s^{2}(2-\beta)} \\
= & \frac{2[\beta(\alpha+s)+2(1-s)]}{2(4-\beta \gamma)-s^{2}(2-\beta)}=p_{1} \\
q_{2}= & \alpha+s\left[1-\frac{s\{\beta(\alpha+s)+2(1-s)\}}{2(4-\beta \gamma)-s^{2}(2-\beta)}\right] \\
& -\frac{\left(4-s^{2}\right)(\alpha+s)+\left(2 \gamma-s^{2}\right)(1-s)}{2(4-\beta \gamma)-s^{2}(2-\beta)} \\
& +\frac{2 \gamma[\beta(\alpha+s)+2(1-s)]}{2(4-\beta \gamma)-s^{2}(2-\beta)} \\
= & \frac{\left(4-s^{2}\right)(\alpha+s)+\left(2 \gamma-s^{2}\right)(1-s)}{2(4-\beta \gamma)-s^{2}(2-\beta)}=\theta p_{2}
\end{aligned}
$$

$$
\Pi_{1}=p_{1} q_{1}-\varepsilon^{2}=\frac{\left(4-s^{2}\right)[\beta(\alpha+s)+2(1-s)]^{2}}{\left[2(4-\beta \gamma)-s^{2}(2-\beta)\right]^{2}}
$$

$$
\Pi_{2}=p_{2} q_{2}=\frac{\left[\left(4-s^{2}\right)(\alpha+s)+\left(2 \gamma-s^{2}\right)(1-s)\right]^{2}}{\theta\left[2(4-\beta \gamma)-s^{2}(2-\beta)\right]^{2}}
$$


Table 2 Optimal prices, sales and profits of the traditional and online retailers and the optimal effort put in by the traditional retailer to counter showrooming

\begin{tabular}{lll}
\hline & Traditional retailer & Online retailer \\
\hline Optimal price & $\frac{2[\beta(\alpha+s)+2(1-s)]}{2(4-\beta \gamma)-s^{2}(2-\beta)}$ & $\frac{\left(4-s^{2}\right)(\alpha+s)+\left(2 \gamma-s^{2}\right)(1-s)}{\theta\left[2(4-\beta \gamma)-s^{2}(2-\beta)\right]}$ \\
Optimal sales & $\frac{2[\beta(\alpha+s)+2(1-s)]}{2(4-\beta \gamma)-s^{2}(2-\beta)}$ & $\frac{\left(4-s^{2}\right)(\alpha+s)+\left(2 \gamma-s^{2}\right)(1-s)}{2(4-\beta \gamma)-s^{2}(2-\beta)}$ \\
Optimal profit & $\frac{\left(4-s^{2}\right)[\beta(\alpha+s)+2(1-s)]^{2}}{\left[2(4-\beta \gamma)-s^{2}(2-\beta)\right]^{2}}$ & $\frac{\left[\left(4-s^{2}\right)(\alpha+s)+\left(2 \gamma-s^{2}\right)(1-s)\right]^{2}}{\theta\left[2(4-\beta \gamma)-s^{2}(2-\beta)\right]^{2}}$ \\
Optimal effort & $\frac{s[\beta(\alpha+s)+2(1-s)]}{2(4-\beta \gamma)-s^{2}(2-\beta)}$ & \\
\hline
\end{tabular}

Table 2 shows the optimal prices, sales and profits of the traditional and online retailers and the optimal effort put in by the traditional retailer to counter showrooming.

It can be proved that the price, sales volume and profit of the traditional retailer are still higher than those for the online retailer post-investment made by the traditional retailer to counter showrooming.

Further, it can be shown from Eqs. (12-(18) that the Nash equilibrium prices, sales volumes and profits of both the retailers assume fractional values under normalized demand functions; also, $0<\varepsilon<1$, as defined.

Proposition (5) checks if the price, demand/sales volume and profit of the traditional retailer increase upon investment made to counter showrooming.

Proposition 5 The following hold for the traditional retailer:

\section{(a) Price charged increases.}

(b) Demand/sales volume increases.

(c) Profit increases given $\gamma>0.064$.

Part (c) of Proposition (5) highlights the fact that the profit of the traditional retailer may not always increase upon investment made to counter showrooming. This is clear from Eq. (17) that although the price and demand/sales volume of the traditional retailer, and hence the revenue, increase post-investment, as shown in parts (a) and (b) of Proposition (5), the investment made may actually bring down the profit below the pre-investment level depending on the choice of parameter values. Therefore, the traditional retailer has to weigh options before making any investment to counter showrooming and would wish to invest only when the benefits outweigh the cost. Part (c) of Proposition (5) shows that when $\gamma>0.064$, for any combination of other parameter values, the profit of the traditional retailer always increases postinvestment.

Proposition 6 The following hold for the online retailer post-investment by the traditional retailer:

(a) Price charged decreases.

(b) Demand/sales volume decreases.

(c) Profit decreases.

Proposition (6) shows that the online retailer loses upon the traditional retailer's investment to counter showrooming.

A sensitivity analysis of the traditional and online retailers' profits with respect to the parameters, $\alpha, \beta, \gamma$, $\theta$ and $s$ shows similar trends as observed for the base case. The sensitivity of the traditional retailer's effort, $\varepsilon$ against various parameters is shown in Appendix 2. Figure 6 shows that as $\alpha$ increases, the market potential of the online retailer increases, resulting in an increased effort put in by the traditional retailer. Figure 7 shows that the traditional retailer's effort increases with the showrooming parameter, $s$, but with a decreasing return to scale. This may be attributed to the cost of effort, which is quadratic in nature, and therefore increases with effort with an increasing return to scale. While the traditional retailer's effort is independent of $\theta$, Figs. 8 and 9 show that the same increases with the cross-price sensitivity parameters, $\beta$ and $\gamma$, respectively.

Proposition 7 The combined offline and online demand, $q_{1}+q_{2}$, decreases post-investment by the traditional retailer.

Proposition (7) shows that although the traditional retailer benefits at the cost of the online retailer by making an investment to counter showrooming, the combined offline and online customer demand/sales volume falls below the pre-investment level. This result indicates a contraction of the overall market demand/sales volume post the traditional retailer's investment to counter showrooming. It may be noted from the proof of Proposition (7) shown in Appendix 1 that the result is contingent upon the assumption, $\beta>\gamma$. When $\beta=\gamma$, the pre-investment combined 
offline and online demand remains the same postinvestment.

A sensitivity analysis of the pre- and post-investment combined offline and online demand with respect to the parameters, $\alpha, \beta, \gamma$ and $s$ is shown in Appendix 2. It may be observed from Figs. 10, 11, 12 and 13 that the combined demands pre- and postinvestment are almost the same with the pre-investment combined demand marginally exceeding the post-investment combined demand. Figure 10 shows that the combined demand increases with $\alpha$ as the market potential of the online retailer increases with the difference between pre- and post-investment combined demands marginally increasing with $\alpha$. Figure 11 shows that the combined offline and online demand pre- and post-investment marginally increases with the showrooming parameter, $s$ with the difference between pre- and post-investment combined demands marginally increasing with $s$. Figures 12 and 13 show that the combined offline and online demand pre- and post-investment increases with the parameters, $\beta$ and $\gamma$, respectively. While the difference between pre- and post-investment combined demands marginally increases with $\beta$, the same marginally decreases with $\gamma$ and becomes zero when $\gamma$ equals $\beta$.

Online entry by the traditional retailer to counter showrooming

The traditional retailer can make a foray into the online market to counter the effect of showrooming. Therefore, the traditional retailer sells both offline and online. While it sets the offline price, the online price is set by its online arm along with the online retailer, and the prices charged by the online arm of the traditional retailer and the online retailer are the same, thereby creating an undifferentiated online marketplace for the online customer. This is in line with the assumption made by Balakrishnan et al. (2014). Hence, we have the following offline and online demand functions, respectively:

$$
\begin{aligned}
& q_{1}=(1-s)-p_{1}+\beta \theta p_{2} \\
& q_{2}=(\alpha+s)-\theta p_{2}+\gamma p_{1}
\end{aligned}
$$

While the offline demand can be attributed solely to the traditional retailer, the online demand has to be apportioned to the traditional and online retailers. Let $\lambda q_{2}(0<\lambda<1)$ of the online demand be attributed to the online arm of the traditional retailer and $(1-\lambda) q_{2}$ of the online demand be attributed to the online retailer. This is also in line with the assumption made by Balakrishnan et al. (2014).

Therefore, offline and online sales of the traditional retailer $=q_{1}+\lambda q_{2}$ and online sales of the online retailer $=(1-\lambda) q_{2}$.

The profit functions for the traditional and online retailers can be written as follows, respectively:

$$
\begin{aligned}
\Pi_{1}= & p_{1} q_{1}+\lambda p_{2} q_{2} \\
= & p_{1}\left[(1-s)-p_{1}+\beta \theta p_{2}\right] \\
& +\lambda p_{2}\left[(\alpha+s)-\theta p_{2}+\gamma p_{1}\right] \\
& \\
\Pi_{2}= & (1-\lambda) p_{2} q_{2}=(1-\lambda) p_{2}\left[(\alpha+s)-\theta p_{2}+\gamma p_{1}\right]
\end{aligned}
$$

The fixed cost/investment for setting up an online arm by the traditional retailer has not been included in its profit function. It is assumed that the traditional retailer will consider setting up an online arm only if the benefits outweigh the fixed cost/investment.

Now, partially differentiating the profit functions with respect to their prices, equating them to zero and solving the equations, we get the following Nash equilibrium prices:

$$
\begin{aligned}
& p_{1}=\frac{(\beta \theta+\lambda \gamma)(\alpha+s)+2 \theta(1-s)}{\theta(4-\beta \gamma)-\lambda \gamma^{2}} \\
& p_{2}=\frac{2(\alpha+s)+\gamma(1-s)}{\theta(4-\beta \gamma)-\lambda \gamma^{2}}
\end{aligned}
$$

The following are the expressions for $q_{1}$ and $q_{2}$ :

$$
\begin{aligned}
q_{1} & =(1-s)-\frac{(\beta \theta+\lambda \gamma)(\alpha+s)+2 \theta(1-s)}{\theta(4-\beta \gamma)-\lambda \gamma^{2}} \\
& +\beta \theta \frac{2(\alpha+s)+\gamma(1-s)}{\theta(4-\beta \gamma)-\lambda \gamma^{2}} \\
& =\frac{(\beta \theta-\lambda \gamma)(\alpha+s)+\left(2 \theta-\lambda \gamma^{2}\right)(1-s)}{\theta(4-\beta \gamma)-\lambda \gamma^{2}}
\end{aligned}
$$

$$
\begin{aligned}
q_{2}= & (\alpha+s)-\theta \frac{2(\alpha+s)+\gamma(1-s)}{\theta(4-\beta \gamma)-\lambda \gamma^{2}} \\
& +\gamma \frac{(\beta \theta+\lambda \gamma)(\alpha+s)+2 \theta(1-s)}{\theta(4-\beta \gamma)-\lambda \gamma^{2}} \\
= & \frac{\theta[2(\alpha+s)+\gamma(1-s)]}{\theta(4-\beta \gamma)-\lambda \gamma^{2}}
\end{aligned}
$$


Table 3 Optimal prices, sales and profits of the traditional and online retailers upon online entry by the traditional retailer to counter showrooming

\begin{tabular}{lll}
\hline & Traditional retailer & Online retailer \\
\hline Optimal price & $p_{1}=\frac{(\beta \theta+\lambda \gamma)(\alpha+s)+2 \theta(1-s)}{\theta(4-\beta \gamma)-\lambda \gamma^{2}}$ & $p_{2}=\frac{2(\alpha+s)+\gamma(1-s)}{\theta(4-\beta \gamma)-\lambda \gamma^{2}}$ \\
Optimal sales & Offline & $(1-\lambda) q_{2}=(1-\lambda) \frac{\theta[2(\alpha+s)+\gamma(1-s)]}{\theta(4-\beta \gamma)-\lambda \gamma^{2}}$ \\
& $q_{1}=\frac{(\beta \theta-\lambda \gamma)(\alpha+s)+\left(2 \theta-\lambda \gamma^{2}\right)(1-s)}{\theta(4-\beta \gamma)-\lambda \gamma^{2}}$ & \\
& Online & \\
& $\lambda q_{2}=\lambda \frac{\theta[2(\alpha+s)+\gamma(1-s)]}{\theta(4-\beta \gamma)-\lambda \gamma^{2}}$ & $(1-\lambda) p_{2} q_{2}$ \\
\hline
\end{tabular}

Table 3 shows the optimal prices, sales and profits of the traditional and online retailers upon online entry by the traditional retailer to counter showrooming.

Proposition (8) shows that the price, sales volume (offline + online) and profit of the traditional retailer are higher than those of the online retailer, respectively.

Proposition 8 The following will hold:
(a) $p_{1}>p_{2}$
(b) $q_{1}+\lambda q_{2}>(1-\lambda) q_{2}$
(c) $\Pi_{1}>\Pi_{2}$

Proposition 9 The following will hold for the traditional retailer post its entry into the online market:

(a) Price charged increases.

(b) Offline sales volume decreases. However, total sales (offline and online) increase.

(c) Profit increases.

Proposition (9) shows that upon online entry by the traditional retailer, even if its profit from offline sales may decrease, its total profit from offline and online sales will increase. This observation is similar to that made by Bernstein et al. (2008). Also, Gao and Su (2017) note that if showrooming customers are persuaded to purchase from the traditional retailer's online channel, it may benefit the traditional retailer.

Proposition 10 The following will hold for the online retailer post the traditional retailer's entry into the online market: (a) Price charged increases.

(b) Sales volume decreases.

(c) Profit decreases.

The results of Propositions (9) and (10) are in line with the observations made by Balakrishnan et al. (2014).

Sensitivity analyses of the traditional and online retailers' profits against different parameter values have been performed and are shown in Appendix 2. Figure 14 shows that for higher values of $\lambda(\geq 0.4)$, profits of both the traditional and online retailers, as well as their difference, increase with $\alpha$, as the potential of the online market increases. This is in contrast to the base case where the difference decreases with $\alpha$. The reason may be attributed to the fact that now the traditional retailer, besides selling in the offline market, has forayed into the online market, and therefore, whenever the online market expands, given that the traditional retailer has a significant share of the online market $(\lambda \geq 0.4)$, its profit increases faster than the online retailer's profit with $\alpha$, making the difference in their profits an increasing function of $\alpha$. Hence, it may be concluded that when the traditional retailer enters into the online market and gains a significant market share, the results derived in this paper still hold, independent of the assumptions made for model development. A similar conclusion may be drawn for the sensitivity of the retailers' profits against the showrooming parameter, $s$. As shown in Fig. 15, the nature of the graph is the same as that for the base case; however, for a significant online market share of the traditional retailer $(\lambda \geq 0.4)$, the difference in the retailers' profits, although decreasing with $s$, is still positive within the reasonable range of the parameter, $s$, 
indicating independence of modelling assumptions and robustness of the results derived in the paper. While the trend with respect to $\beta$ remains the same as for the base case, it is observed that the nature of the difference in the retailers' profits with respect to $\theta$ and $\gamma$ reverses in comparison with the same for the base case for higher values of $\lambda$. Figure 16 shows the sensitivity of the retailers' profits against $\lambda$. It may be intuitively explained that as the traditional retailer's share of the online market increases, its profit increases, the online retailer's profit decreases, and as a result, the difference in their profits increases.

Proposition 11 The following will hold post the traditional retailer's entry into the online market:

(a) Total online sales of the online arm of the traditional retailer and online retailer increase.

(b) Total offline and online sales decrease.

Proposition (11) shows that upon the traditional retailer's entry into the online market, although the online market expands, the total market size, including offline and online sales, contracts.

A sensitivity analysis of the combined offline and online demand, pre- and post-online entry by the traditional retailer, has been performed and is shown in Appendix 2. It has been found that the trend with respect to the parameters, $\alpha, \beta, \gamma$ and $s$ is more or less similar to that for the case when the traditional retailer puts in effort to counter showrooming. Figure 17 shows that while the combined demand, pre-online entry by the traditional retailer, is independent of $\theta$, the same, post-online entry by the traditional retailer, marginally increases with $\theta$, reducing the difference between the two. On the other hand, Fig. 18 shows that while the combined demand, pre-online entry by the traditional retailer, is independent of $\lambda$, the same, postonline entry by the traditional retailer, marginally decreases with $\lambda$, increasing the difference between the two.

\section{Sequential move by the retailers to set prices}

In this game, one of the retailers acts as the Stackelberg leader and the other acts as the follower. The leader moves first and sets its price. The follower then makes its move and sets its price based on the price set by the leader. To reach equilibrium, the leader derives the follower's best response function and incorporates it into its profit function to determine its price. Subsequently, the follower determines its price by observing the price set by the leader.

Traditional retailer as the leader and online retailer as the follower

Given a price, $p_{1}$ set by the traditional retailer, we get the best price for the online retailer as $p_{2}=\frac{\alpha+s+\gamma p_{1}}{2 \theta}$. Incorporating the expression for $p_{2}$ in the profit function for the traditional retailer as given in Eq. (1), we get

$$
\Pi_{1}=p_{1}\left[(1-s)-p_{1}+\frac{\beta}{2}\left(\alpha+s+\gamma p_{1}\right)\right]
$$

Now, differentiating the above profit function and equating it to zero, we obtain the following:

$p_{1}=\frac{\beta(\alpha+s)+2(1-s)}{2(2-\beta \gamma)}$

It can be easily shown that $\Pi_{1}$ is concave in $p_{1}$. Therefore, $p_{1}$, as obtained in Eq. (25), maximizes $\Pi_{l}$.

Also, the following expressions may be obtained:

$p_{2}=\frac{(4-\beta \gamma)(\alpha+s)+2 \gamma(1-s)}{4 \theta(2-\beta \gamma)}$

$q_{1}=\frac{\beta(\alpha+s)+2(1-s)}{4}$

$q_{2}=\frac{(4-\beta \gamma)(\alpha+s)+2 \gamma(1-s)}{4(2-\beta \gamma)}$

$\Pi_{1}=\frac{[\beta(\alpha+s)+2(1-s)]^{2}}{8(2-\beta \gamma)}$

$\Pi_{2}=\frac{[(4-\beta \gamma)(\alpha+s)+2 \gamma(1-s)]^{2}}{\theta[4(2-\beta \gamma)]^{2}}$

Table 4 shows the optimal prices, sales and profits of the traditional and online retailers when the traditional retailer acts as the Stackelberg leader.

Proposition 12 The following will hold when the traditional retailer acts as the leader and the online retailer acts as the follower, in comparison with when both the retailers move simultaneously to set their respective prices: 
Table 4 Optimal prices, sales and profits of the traditional and online retailers when the traditional retailer acts as the Stackelberg leader

\begin{tabular}{lll}
\hline & Traditional retailer & Online retailer \\
\hline Optimal price & $\frac{\beta(\alpha+s)+2(1-s)}{2(2-\beta \gamma)}$ & $\frac{(4-\beta \gamma)(\alpha+s)+2 \gamma(1-s)}{4 \theta(2-\beta \gamma)}$ \\
Optimal sales & $\frac{\beta(\alpha+s)+2(1-s)}{4}$ & $\frac{(4-\beta \gamma)(\alpha+s)+2 \gamma(1-s)}{4(2-\beta \gamma)}$ \\
Optimal profit & $\frac{[\beta(\alpha+s)+2(1-s)]^{2}}{8(2-\beta \gamma)}$ & $\frac{[(4-\beta \gamma)(\alpha+s)+2 \gamma(1-s)]^{2}}{\theta[4(2-\beta \gamma)]^{2}}$ \\
\hline
\end{tabular}

(a) Prices of both the retailers increase.

(b) While offline sales decrease, online sales increase.

(c) Profits of both the retailers increase.

(d) Total offline and online sales decrease.

Online retailer as the leader and traditional retailer as the follower

Given a price, $p_{2}$ set by the online retailer, we get the best price for the traditional retailer as $p_{1}=\frac{1-s+\beta \theta p_{2}}{2}$. Incorporating the expression for $p_{1}$ in the profit function for the online retailer as given in Eq. (2), we get

$$
\Pi_{2}=p_{2}\left[(\alpha+s)-\theta p_{2}+\frac{\gamma}{2}\left(1-s+\beta \theta p_{2}\right)\right]
$$

Now, differentiating the above profit function and equating it to zero, we obtain the following:

$p_{2}=\frac{2(\alpha+s)+\gamma(1-s)}{2 \theta(2-\beta \gamma)}$

It can be easily shown that $\Pi_{2}$ is concave in $p_{2}$. Therefore, $p_{2}$, as obtained in Eq. (31), maximizes $\Pi_{2}$.

Also, the following expressions may be obtained:

$$
\begin{aligned}
& p_{1}=\frac{2 \beta(\alpha+s)+(4-\beta \gamma)(1-s)}{4(2-\beta \gamma)} \\
& q_{1}=\frac{2 \beta(\alpha+s)+(4-\beta \gamma)(1-s)}{4(2-\beta \gamma)} \\
& q_{2}=\frac{2(\alpha+s)+\gamma(1-s)}{4}
\end{aligned}
$$

Table 5 Optimal prices, sales and profits of the traditional and online retailers when the online retailer acts as the Stackelberg leader

\begin{tabular}{lll}
\hline & Traditional retailer & Online retailer \\
\hline Optimal price & $\frac{2 \beta(\alpha+s)+(4-\beta \gamma)(1-s)}{4(2-\beta \gamma)}$ & $\frac{2(\alpha+s)+\gamma(1-s)}{2 \theta(2-\beta \gamma)}$ \\
Optimal sales & $\frac{2 \beta(\alpha+s)+(4-\beta \gamma)(1-s)}{4(2-\beta \gamma)}$ & $\frac{2(\alpha+s)+\gamma(1-s)}{4}$ \\
Optimal profit & $\frac{[2 \beta(\alpha+s)+(4-\beta \gamma)(1-s)]^{2}}{[4(2-\beta \gamma)]^{2}}$ & $\frac{[2(\alpha+s)+\gamma(1-s)]^{2}}{8 \theta(2-\beta \gamma)}$ \\
\hline
\end{tabular}

$\Pi_{1}=\frac{[2 \beta(\alpha+s)+(4-\beta \gamma)(1-s)]^{2}}{[4(2-\beta \gamma)]^{2}}$

$\Pi_{2}=\frac{[2(\alpha+s)+\gamma(1-s)]^{2}}{8 \theta(2-\beta \gamma)}$

Table 5 shows the optimal prices, sales and profits of the traditional and online retailers when the online retailer acts as the Stackelberg leader.

Proposition 13 The following will hold when the online retailer acts as the leader and the traditional retailer acts as the follower, in comparison with when both the retailers move simultaneously to set their respective prices:

(a) Prices of both the retailers increase.

(b) While offline sales increase, online sales decrease.

(c) Profits of both the retailers increase.

(d) Total offline and online sales decrease.

Proposition (14) shows the relationships between prices, sales volumes and profits of each of the retailers under simultaneous and sequential moves.

Proposition 14 Let the superscript 'Sim' denote the game when the retailers make simultaneous moves. Also, let the superscripts 'Seq $(T R=L)$ ' and 'Seq $(O R=L)$ ' denote the games when the traditional retailer $(T R)$ is the leader $(L)$ and when the online retailer $(O R)$ is the leader $(L)$ under sequential moves, respectively. Then, the following will hold:
(a) $\quad p_{1}^{\operatorname{Seq}(T R=L)}>p_{1}^{\operatorname{Seq}(O R=L)}>p_{1}^{\operatorname{Sim}}$
(b) $q_{1}^{\operatorname{Seq}(O R=L)}>q_{1}^{\operatorname{Sim}}>q_{1}^{\operatorname{Seq}(T R=L)}$
(c) $\Pi_{1}^{\operatorname{Seq}(O R=L)}>\Pi_{1}^{\operatorname{Seq}(T R=L)}>\Pi_{1}^{\mathrm{Sim}}$ 
(d) $p_{2}^{\operatorname{Seq}(O R=L)}>p_{2}^{\operatorname{Seq}(T R=L)}>p_{2}^{\operatorname{Sim}}$

(e) $q_{2}^{\operatorname{Seq}(T R=L)}>q_{2}^{\operatorname{Sim}}>q_{2}^{\operatorname{Seq}(O R=L)}$

(f) $\Pi_{2}^{\operatorname{Seq}(T R=L)}>\Pi_{2}^{\operatorname{Seq}(O R=L)}>\Pi_{2}^{\operatorname{Sim}}$

(g) $\left(q_{1}+q_{2}\right)^{\operatorname{Sim}}$

$>\left(q_{1}+q_{2}\right)^{\operatorname{Seq}(O R=L)}>\left(q_{1}+q_{2}\right)^{\operatorname{Seq}(T R=L)}$

The above are standard results for upward sloping reaction curves (see, for example, Gal-Or 1985).

\section{Summary of results and managerial implications}

The important results of this research that provide significant managerial insights are the following:

When the traditional retailer adopts no strategy to counter showrooming:

(a) Showrooming hurts the traditional retailer and benefits the online retailer by decreasing the sales volume and profit for the former and increasing the same for the latter.

(b) The overall market demand, including offline and online sales, increases under showrooming, thereby benefitting the market. Although sales and profits of the traditional retailer may decline in the short run, the overall expansion of the market provides it with an opportunity to benefit in the long run.

(c) When the market potential of online sales increases at the same level of showrooming, sales volumes and profits of both retailers increase.

When the traditional retailer adopts a strategy to counter showrooming:

(a) The traditional retailer is better off, and the online retailer is worse off, when the traditional retailer adopts a counter-strategy to mitigate the ill effects of showrooming.

(b) The combined offline and online sales decrease post-adoption of a strategy by the traditional retailer to counter showrooming, thereby contracting the market.

(c) When the traditional retailer makes an online entry, its offline sales decrease, but its total offline and online sales increase. (d) When the traditional retailer makes an online entry, total online sales and the online retail price increase.

(e) Sensitivity analyses reveal that the results of this study even hold for wide ranges of parameter values when the traditional retailer enters into the online market, making them robust and independent of modelling assumptions.

When one of the retailers acts as the Stackelberg leader:

(a) Both the traditional and online retailers achieve higher sales volumes in sequential moves when the other retailer acts as the leader than in the simultaneous move.

(b) Both the traditional and online retailers make higher profits in sequential moves than in the simultaneous move and the higher profit made by a retailer in sequential moves is when the other retailer acts as the leader.

(c) The combined offline and online sales decrease in sequential moves than in the simultaneous move and the overall market demand is the lowest when the traditional retailer acts as the leader.

Results show that as long as the market potential of offline sales exceeds that of online sales, which is the present situation given that in the USA, online retail sales account for only $10 \%$ of total retail sales, as mentioned before, and online customers are more price-sensitive than offline customers, traditional retailers need not worry about competitiveness against online retailers as the sales volumes and profits of traditional retailers are always higher than those for online retailers at all levels of showrooming. It is only when the market potential of online sales increases as a result of showrooming that traditional retailers need to devise a counter-strategy to arrest the decline in their sales volumes and profits. Traditional retailers need not bother about price-sensitive showroomers because they are anyway online shoppers and would not buy from a traditional store, and hence there is not much that traditional retailers can do to make them shop in a traditional store. However, shoppers that showroom based on non-price factors, such as flexibility and delivery convenience, can be converted to in-store buyers, and traditional retailers must focus on them so that they are compelled to buy in-store rather than 
switching to an online retailer. In fact, it is shown in this paper that if traditional retailers invest to counter showrooming, their sales volumes and profits might actually improve at the expense of online retailers. Therefore, instead of taking defensive strategies to counter showrooming, as mentioned in the extant literature (See, for example, Moran 2013; Teixeira and Gupta 2015), such as price matching, charging a fee for showrooming, not allowing mobile devices or disabling Wi-fi and internet in store, which are shortterm and would drive shoppers away from stores, managers of traditional stores should accept showrooming as an unavoidable phenomenon and leverage the opportunity to reap benefits for their stores (Wohlsen 2012). Even if the sales volumes and profits of traditional retailers decline under showrooming, they can leverage the overall expansion of the market in the long run. Moreover, traditional retailers need not worry about showrooming because if the market potential of online sales increases at the same level of showrooming, it not only benefits online retailers, but also increases the sales volumes and profits of traditional retailers.

As shown in the paper, improved in-store shopping experience has the potential to not only convert some confirmed showroomers into in-store buyers, but also increase the overall market potential of traditional stores. Traditional retailers may focus on the factors that put online shopping at a disadvantage against shopping in physical stores, such as touch-and-feel experience, personal encounter with sales people, response to product-related queries, customized instore service, instant gratification, delivery, installation and maintenance of products at home, after-sales service and contact information of service personnel, and ease of return in case of defects and product dissatisfaction (Quint et al. 2013). Therefore, it is imperative for traditional retailers to redesign the store layout and make it more attractive and visually appealing with a prominent display of products and installation of touchpads for easy dissemination of product-related information. Store sales people should be knowledgeable enough to address any shopper query and properly trained to be courteous and friendly with shoppers to provide them with a feelgood in-store experience (Quint et al. 2013; Sawhney et al. 2017). Viejo-Fernandez et al. (2020) note that instore smartphone users are more likely to pay a higher price depending on their in-store service experience, thus making them of special interest to traditional retailers. Cross-selling and high-quality interactions between sales people and customers are considered to be effective strategies for selling to showroomers while they are in store (Fassnacht et al. 2019; Rajkumar et al. 2021). Shankar et al. (2021) also highlight the importance of in-store service convenience to manage showrooming. Schneider and Zielke (2021) comment that traditional retailers should focus on the qualification and competence of sales people as a long-term strategy to counter showrooming. Frasquet and Miquel-Romero (2021), based on the pushpull-mooring framework, also find that the mooring factors, i.e. the quality of in-store sales people and relationship between customers and the retailer, based on customer trust, satisfaction and loyalty, play a significant role in reducing competitive showrooming. By focusing more on pre- and post-sale value-added services, traditional stores may differentiate themselves from online stores and provide shoppers with more value-for-time and value-for-money (Freeman 2014; Sit et al. 2018). They should focus more on services than on products, i.e. 'servicization' of products, and sell a complete package of which products are only a part (Sawhney et al. 2017). The other strategy discussed in this paper is the traditional retailer's online entry, i.e. omnichannel retailing, which has also been found effective. When the traditional retailer sets up an online store, besides its physical store, showroomers have an option to check products in the physical store and buy from the traditional retailer's online store, which although brings down offline sales, boosts the combined offline and online sales. The essence of the findings of this research points to the fact that traditional stores will be better off if they embrace showrooming as a natural phenomenon and adopt innovative strategies to mitigate the ill effects of showrooming rather than taking a defensive approach to counter it.

\section{Conclusions, limitations of the study and directions for future research}

In this paper, we have developed economic models of price competition between a traditional and an online retailer under customer showrooming behaviour. We have shown that showrooming hurts the traditional retailer and benefits the online retailer. However, the 
overall market demand, including offline and online sales, increases under showrooming. We have also considered two strategies-effort/investment made and online entry by the traditional retailer - to counter showrooming and observed that while the strategies benefit the traditional retailer and hurt the online retailer, the overall market demand declines. In particular, when the traditional retailer makes an online entry, although its physical sales decrease, its total sales increase, and also, although the sales of the online retailer decrease, the online market expands and the online retail price increases. We have developed economic models under both simultaneous and sequential moves made by the retailers. It has been observed that both the retailers make higher profits under sequential moves than in the simultaneous move. However, the overall market demand is lower under sequential moves than in the simultaneous move. We have also performed sensitivity analyses for different ranges of parameter values to check for robustness of the results. We comment that the traditional retailer is better off if it accepts showrooming as an inevitable phenomenon and adopts innovative strategies to mitigate its negative impacts, rather than taking short-term, defensive strategies to counter it. Almost all the proofs (except one), shown in this paper, hold for the entire ranges of the parameter values, thereby making the results robust and not dependent on specific parameter ranges.

\section{Limitations of the study}

One of the assumptions of this study is that the market potential of offline sales is higher than that of online sales, which is practical under the present circumstances. Therefore, the results of this research are valid under this assumption. However, as online sales are growing faster than offline sales, especially under the current COVID-19 situation, the assumption may be relaxed and a detailed sensitivity analysis may need to be carried out to check under what conditions the results still remain valid or otherwise. Although a preliminary sensitivity analysis has been performed in this paper to check for robustness of the results, a detailed sensitivity analysis is needed to be designed for a thorough analysis.

In this paper, we have considered showrooming as an exogenous parameter. However, as mentioned in the literature review, many authors have considered showrooming as an endogenous factor, depending on the sales/advertising effort. Therefore, there is a further need to compare the results of this paper with those obtained by considering the showrooming behaviour as an endogenous factor in more detail. Moreover, models may be developed considering showrooming as both an exogenous and an endogenous factor.

Models developed in this paper assume linear demand functions. As mentioned in the literature review, there is another class of relevant literature that models showrooming based on the utility theory. Therefore, there is a need to compare the results of this paper with those obtained based on the utility theory.

In this paper, we have considered competition between a traditional retailer and an online retailer. It is to be seen for a dual-channel supply chain involving a manufacturer/supplier, a traditional retailer and an online retailer, how the models developed in this paper need to be revised and how the results compare with those for a different problem set-up.

\section{Directions for future research}

In this paper, we have considered showrooming. One possible direction for future research is to consider the reverse of showrooming, i.e. webrooming where shoppers search for product information and compare prices on the internet and then visit and buy from a physical store. A related extension could be crosschannel free riding, i.e. simultaneous existence of showrooming and webrooming (Chen et al. 2018). A more general research direction would be to consider omnichannel retailing that provides shoppers with a seamless shopping experience through multiple channels such as physical and online stores, mobile devices, social media, desktops, televisions, telephones and catalogues. In omnichannel retailing, shoppers may search for product information on one channel, experience products on a different channel, place purchase orders on another channel, pick up the orders from yet another channel or get them delivered at home. The implication for traditional retailers in omnichannel retailing is that they can fulfil online orders either from their distribution centres or from their physical stores. The implication for online retailers in omnichannel retailing is that they can open showrooms where shoppers may experience or try on products before purchasing them online. There has 
been some recent research on webrooming and omnichannel retailing (see, for example, Jing 2018 and Zhang and Zhang 2020 for webrooming, and Brynjolfsson et al. 2013; Gao and Su 2017; Sopadjieva et al. 2017; Bell et al. 2018; Chen et al. 2018; von Briel 2018; Wiener et al. 2018 and Gupta et al. 2019 for omnichannel retailing). However, we feel there are still ample opportunities for research in these areas. Finally, in this paper, we have not considered product returns. Generally, product returns are higher in online retail than in offline retail. The effect of omnichannel retailing on product returns (see, for example, He et al. 2020; Li et al. 2020 and Liu et al. 2020) could also be an interesting direction for future research.

Acknowledgements The author is grateful to the anonymous reviewer for valuable comments and suggestions that helped improve the content and presentation of the paper to a great extent.

Funding The author did not seek or receive any funding for this research.

Declarations

Conflict of interest The author declares no conflict of interest.

\section{Appendix 1}

\section{Proof of Proposition 1}

(a) Suppose the inequality holds. Then,

$$
\begin{aligned}
p_{1}>p_{2} \Rightarrow & \frac{\beta(\alpha+s)+2(1-s)}{4-\beta \gamma} \\
& >\frac{2(\alpha+s)+\gamma(1-s)}{\theta(4-\beta \gamma)} \\
\Rightarrow & \theta[\beta(\alpha+s)+2(1-s)] \\
& >2(\alpha+s)+\gamma(1-s) \quad(\because 4-\beta \gamma>0)
\end{aligned}
$$

Since $\theta>1$, it would suffice to show $\beta(\alpha+s)+2(1-s)>2(\alpha+s)+\gamma(1-s)$.

This follows $(2-\gamma)(1-s)>(2-\beta)(\alpha+s)$. Since by assumption $1-s>\alpha+s$ and $2-\gamma>2-\beta(\because \beta>\gamma)$, the inequality holds and $p_{1}>p_{2}$.

(b) Suppose the inequality holds. Then

$$
\begin{aligned}
q_{1}>q_{2} \Rightarrow & \frac{\beta(\alpha+s)+2(1-s)}{4-\beta \gamma} \\
& >\frac{2(\alpha+s)+\gamma(1-s)}{4-\beta \gamma} \\
\Rightarrow & \beta(\alpha+s)+2(1-s) \\
& >2(\alpha+s)+\gamma(1-s) \quad(\because 4-\beta \gamma>0)
\end{aligned}
$$

As shown in part (a), the inequality holds and $q_{1}>q_{2}$.

(c) Suppose the inequality holds. Then

$$
\begin{gathered}
\Pi_{1}>\Pi_{2} \quad \Rightarrow \quad p_{1} q_{1}>p_{2} q_{2} \quad \Rightarrow \\
q_{1}^{2}>\frac{q_{2}^{2}}{\theta} \quad \Rightarrow \quad q_{1}>\frac{q_{2}}{\sqrt{\theta}}
\end{gathered}
$$

Since in part (b), it is already shown $q_{1}>q_{2}$, it follows $q_{1}>q_{2}>\frac{q_{2}}{\sqrt{\theta}} \quad(\because \theta>1)$. Therefore, the inequality holds and $\Pi_{1}>\Pi_{2}$.

Proof of Proposition 2 Equation (3) can be rewritten as follows:

$p_{1}=\frac{\beta(\alpha+s)+2(1-s)}{4-\beta \gamma}=\frac{2+\alpha \beta-(2-\beta) s}{4-\beta \gamma}$

Since $\beta<1, p_{1}$ decreases with $s$.

Since from Eq. (5), $q_{1}=p_{1}, q_{1}$ also decreases with $s$. Also, since $\Pi_{1}=p_{1} q_{1}, \Pi_{1}$ decreases with $s$.

Eq. (4) can be rewritten as follows:

$p_{2}=\frac{2(\alpha+s)+\gamma(1-s)}{\theta(4-\beta \gamma)}=\frac{2 \alpha+\gamma+(2-\gamma) s}{\theta(4-\beta \gamma)}$

Since $\gamma<1, p_{2}$ increases with $s$.

Since from Eq. (6), $q_{2}=\theta p_{2}, q_{2}$ also increases with $s$.

Also, since $\Pi_{2}=p_{2} q_{2}, \Pi_{2}$ increases with $s$.

Proof of Proposition 3 From Eqs. (5) and (6), we can write

$$
\begin{aligned}
q_{1}+q_{2} & =\frac{\beta(\alpha+s)+2(1-s)}{4-\beta \gamma}+\frac{2(\alpha+s)+\gamma(1-s)}{4-\beta \gamma} \\
& =\frac{2+\alpha \beta+2 \alpha+\gamma+(\beta-\gamma) s}{4-\beta \gamma}
\end{aligned}
$$

Since $\beta>\gamma, q_{1}+q_{2}$ increases with $s$.

Proof of Proposition 4 It is clear from Eqs. (3-8) that prices, sales volumes and profits of both the retailers 
increase with the parameters, $\alpha, \beta$ and $\gamma$. From Eqs. (3), (5) and (7), it may be seen that the price, sales volume and profit of the traditional retailer remain unaffected with change in the parameter, $\theta$. Equations (4), (6) and (8) show that for the online retailer, while the sales volume remains unaffected, the price and profit decrease with the parameter, $\theta$.

\section{Proof of Proposition 5}

(a) To prove, we have to show $\frac{2[\beta(\alpha+s)+2(1-s)]}{2(4-\beta \gamma)-s^{2}(2-\beta)}>\frac{\beta(\alpha+s)+2(1-s)}{(4-\beta \gamma)}$, with reference to Eqs. (3 and 12), which implies $s^{2}(2-\beta)>0$. This is true since $s>0$ and $\beta<1$. Therefore, price charged by the traditional retailer increases upon investment made to counter showrooming.

(b) Since $q_{1}=p_{1}$ for both the scenarios, with reference to Eqs. (5 and 15), the proof follows from part (a).

(c) To prove, we have to show $\frac{\left(4-s^{2}\right)[\beta(\alpha+s)+2(1-s)]^{2}}{\left[2(4-\beta \gamma)-s^{2}(2-\beta)\right]^{2}}>\frac{[\beta(\alpha+s)+2(1-s)]^{2}}{(4-\beta \gamma)^{2}}$, with reference to Eqs. (7 and 17), which implies

$$
\begin{aligned}
& \left(4-s^{2}\right)(4-\beta \gamma)^{2}>\left[2(4-\beta \gamma)-s^{2}(2-\beta)\right]^{2} \\
& \Rightarrow\left(4-s^{2}\right)(4-\beta \gamma)^{2}>4(4-\beta \gamma)^{2}+s^{4} \\
& (2-\beta)^{2}-4 s^{2}(4-\beta \gamma)(2-\beta) \Rightarrow\left(4-s^{2}\right) \\
& (2-\beta)^{2}>\beta^{2}(2-\gamma)^{2}
\end{aligned}
$$

Since $\beta<1,(2-\beta)^{2}>\beta^{2}$. Therefore, it is to be shown $(2-\gamma)^{2}<4-s^{2}$.

Now, by assumption $s<\frac{1-\alpha}{2}$ and $0<\alpha<1$. Therefore, $0<s<0.5$. Now, putting the upper bound on $s$ in the inequality $(2-\gamma)^{2}<4-s^{2}$, we get $(2-\gamma)^{2}<4-$ $0.5^{2}=3.75$ which implies $|2-\gamma|<\sqrt{3.75}=1.936$, i.e. $0.064<\gamma<3.936$. Since $\gamma<1$ by definition, profit of the traditional retailer increases upon investment made to counter showrooming, given $\gamma>0.064$.

\section{Proof of Proposition 6}

(a) To prove, we have to show $\frac{\left(4-s^{2}\right)(\alpha+s)+\left(2 \gamma-s^{2}\right)(1-s)}{\theta\left[2(4-\beta \gamma)-s^{2}(2-\beta)\right]}<\frac{2(\alpha+s)+\gamma(1-s)}{\theta(4-\beta \gamma)}$, with reference to Eqs. (4 and 13). Suppose the inequality holds. Then,

$$
\begin{aligned}
\frac{\left(4-s^{2}\right)(\alpha+s)+\left(2 \gamma-s^{2}\right)(1-s)}{\theta\left[2(4-\beta \gamma)-s^{2}(2-\beta)\right]} \\
<\frac{2(\alpha+s)+\gamma(1-s)}{\theta(4-\beta \gamma)} \\
\Rightarrow \quad\left(4-s^{2}\right)(4-\beta \gamma)(\alpha+s) \\
+\left(2 \gamma-s^{2}\right)(4-\beta \gamma)(1-s)< \\
\quad 2\left[2(4-\beta \gamma)-s^{2}(2-\beta)\right](\alpha+s) \\
+\gamma\left[2(4-\beta \gamma)-s^{2}(2-\beta)\right](1-s) \\
\Rightarrow \quad-\beta(2-\gamma)(\alpha+s)<2(2-\gamma)(1-s) \\
\Rightarrow \quad(2-\gamma)[\beta(\alpha+s)+2(1-s)]>0
\end{aligned}
$$

Since $\gamma<1$, the above is true. Hence, the inequality holds and the price charged by the online retailer decreases post-investment by the traditional retailer.

(b) Since $q_{2}=\theta p_{2}$ for both the scenarios, with reference to Eqs. (6 and 16), the proof follows from part (a).

(c) Since $\Pi_{2}=p_{2} q_{2}$ for both the scenarios, with reference to Eqs. (8 and 18), and both $p_{2}$ and $q_{2}$ decrease, as shown in parts (a) and (b), the profit of the online retailer also decreases postinvestment by the traditional retailer.

Proof of Proposition 7 From Eqs. (5 and 6), we get the pre-investment combined offline and online demand $=\frac{(2+\beta)(\alpha+s)+(2+\gamma)(1-s)}{4-\beta \gamma}$. Also, from Eqs. (15 and 16), we get the post-investment combined offline and online demand $=\frac{\left(4-s^{2}+2 \beta\right)(\alpha+s)+\left(4-s^{2}+2 \gamma\right)(1-s)}{2(4-\beta \gamma)-s^{2}(2-\beta)}$. It is to be shown $\frac{\left(4-s^{2}+2 \beta\right)(\alpha+s)+\left(4-s^{2}+2 \gamma\right)(1-s)}{2(4-\beta \gamma)-s^{2}(2-\beta)}<$ $\frac{(2+\beta)(\alpha+s)+(2+\gamma)(1-s)}{4-\beta \gamma}$.

Suppose the inequality holds. Then, it implies

$\left[2(2+\beta)-s^{2}\right](4-\beta \gamma)(\alpha+s)+[2(2+\quad \gamma)-$ $\left.s^{2}\right](4-\beta \gamma)(1-s)<(2+\beta)\left[2(4-\beta \gamma)-s^{2}(2-\beta)\right]$ $(\alpha+s)+(2+\gamma)\left[2(4-\beta \gamma)-s^{2}(2-\beta)\right](1-s) \Rightarrow$ $-\beta(\beta-\gamma)(\alpha+s)<2(\beta-\gamma)(1-s) \Rightarrow(\beta-\gamma)$ $[\beta(\alpha+s)+2(1-s)]>0$

Since $\beta>\gamma$, the inequality holds and $q_{1}+q_{2}$ decreases post-investment by the traditional retailer.

\section{Proof of Proposition 8}

(a) Suppose the inequality holds. Then, with reference to Eqs. (21 and 22) 


$$
\begin{aligned}
& \frac{(\beta \theta+\lambda \gamma)(\alpha+s)+2 \theta(1-s)}{\theta(4-\beta \gamma)-\lambda \gamma^{2}} \\
& \quad>\frac{2(\alpha+s)+\gamma(1-s)}{\theta(4-\beta \gamma)-\lambda \gamma^{2}} \\
& \Rightarrow(\beta \theta+\lambda \gamma)(\alpha+s)+2 \theta(1-s) \\
& \quad>2(\alpha+s)+\gamma(1-s) \\
& \Rightarrow(2 \theta-\gamma)(1-s)>(2-\beta \theta-\lambda \gamma)(\alpha+s)
\end{aligned}
$$

Since $1-s>\alpha+s$, it would suffice to prove $2 \theta-\gamma>2-\beta \theta-\lambda \gamma \quad$ or $\quad(2+\beta) \theta>2+$ $\gamma-\lambda \gamma$.

Since $\beta>\lambda$ and $\theta>1,(2+\beta) \theta>2+\gamma$. Hence, the inequality holds and $p_{1}>p_{2}$.

(b) The inequality holds for $\lambda \geq 0.5$. However, we have to provide a general proof.

Suppose the inequality holds. Then, $q_{1}+$ $\lambda q_{2}>(1-\lambda) q_{2}$ implies $q_{1}>(1-2 \lambda) q_{2}$ or with reference to Eqs. (23) and (24)

$$
\begin{aligned}
& \frac{(\beta \theta-\lambda \gamma)(\alpha+s)+\left(2 \theta-\lambda \gamma^{2}\right)(1-s)}{\theta(4-\beta \gamma)-\lambda \gamma^{2}} \\
& >(1-2 \lambda) \frac{\theta[2(\alpha+s)+\gamma(1-s)]}{\theta(4-\beta \gamma)-\lambda \gamma^{2}} \\
& \Rightarrow \quad\left[2 \theta-\lambda \gamma^{2}-\gamma \theta(1-2 \lambda)\right](1-s) \\
& >[2 \theta(1-2 \lambda)-\beta \theta+\lambda \gamma](\alpha+s)
\end{aligned}
$$

Since $1-s>\alpha+s$, we have to show $2 \theta-$ $\lambda \gamma^{2}-\gamma \theta(1-2 \lambda)>2 \theta(1-2 \lambda)-\beta \theta+\lambda \gamma$ or $\theta[(\beta-\gamma)+2 \lambda(2+\gamma)]>\lambda \gamma(1+\gamma)$. Since $\beta>\lambda$ and $\theta>1$, it would suffice to show $2 \lambda(2+\gamma)>\lambda \gamma(1+\gamma)$ which is true since $\gamma<1$. Hence, the inequality holds and $q_{1}+\lambda q_{2}>(1-\lambda) q_{2}$.

(c) Suppose the inequality holds. Then, $p_{1} q_{1}+$ $\lambda p_{2} q_{2}>(1-\lambda) p_{2} q_{2}$ or $p_{1} q_{1}>(1-2 \lambda) p_{2} q_{2}$. The inequality holds for $\lambda \geq 0.5$. To provide a general proof, from Eqs. (21-24), we may write

$$
\begin{aligned}
& \frac{(\beta \theta+\lambda \gamma)(\alpha+s)+2 \theta(1-s)}{\theta(4-\beta \gamma)-\lambda \gamma^{2}} \\
& \times \frac{(\beta \theta-\lambda \gamma)(\alpha+s)+\left(2 \theta-\lambda \gamma^{2}\right)(1-s)}{\theta(4-\beta \gamma)-\lambda \gamma^{2}} \\
& >(1-2 \lambda) \frac{2(\alpha+s)+\gamma(1-s)}{\theta(4-\beta \gamma)-\lambda \gamma^{2}} \\
& \times \frac{\theta[2(\alpha+s)+\gamma(1-s)]}{\theta(4-\beta \gamma)-\lambda \gamma^{2}} \\
& \Rightarrow[(\beta \theta+\lambda \gamma)(\alpha+s)+2 \theta(1-s)] \\
& \times\left[(\beta \theta-\lambda \gamma)(\alpha+s)+\left(2 \theta-\lambda \gamma^{2}\right)(1-s)\right] \\
& >\theta(1-2 \lambda)[2(\alpha+s)+\gamma(1-s)]^{2}
\end{aligned}
$$

Now, the coefficient of $(\alpha+s)(1-s)$ in the left hand side of the inequality is $(\beta \theta+\lambda \gamma)(2 \theta-$ $\left.\lambda \gamma^{2}\right)+2 \theta(\beta \theta-\lambda \gamma)=4 \beta \theta^{2}-\lambda \gamma^{2}(\beta \theta+\lambda \gamma)$. Also, the coefficient of $(\alpha+s)(1-s)$ in the right hand side of the inequality is $4 \gamma \theta(1-2 \lambda)$.

Suppose the inequality $4 \beta \theta^{2}-$ $\lambda \gamma^{2}(\beta \theta+\lambda \gamma)>4 \gamma \theta(1-2 \lambda)$ holds. Then, it implies $4 \theta(\beta \theta-\gamma)+\lambda \gamma\left[(8-\beta \gamma) \theta-\lambda \gamma^{2}\right]>0$. Since $0<\lambda, \beta, \gamma<1, \theta>1$ and $\beta>\gamma$, the inequality holds.

Therefore, it would suffice to take the square terms and show

$$
\begin{aligned}
& {\left[2 \theta\left(2 \theta-\lambda \gamma^{2}\right)-\theta \gamma^{2}(1-2 \lambda)\right](1-s)^{2}} \\
& \quad>\left[4 \theta(1-2 \lambda)-\beta^{2} \theta^{2}+\lambda^{2} \gamma^{2}\right](\alpha+s)^{2}
\end{aligned}
$$

Since $1-s>\alpha+s$, we have to show

$$
\begin{aligned}
& 2 \theta\left(2 \theta-\lambda \gamma^{2}\right)-\theta \gamma^{2}(1-2 \lambda) \\
& \quad>4 \theta(1-2 \lambda)-\beta^{2} \theta^{2}+\lambda^{2} \gamma^{2} \\
& \Rightarrow \quad\left(4+\beta^{2}\right) \theta^{2}>\left(4+\gamma^{2}\right) \theta-\lambda\left(8 \theta-\lambda \gamma^{2}\right)
\end{aligned}
$$

Since $0<\lambda, \beta, \gamma<1, \theta>1$ and $\beta>\gamma$, the inequality holds and $\Pi_{1}>\Pi_{2}$.

\section{Proof of Proposition 9}

(a) Comparing Eqs. (3 and 21), it is straightforward to show that the price charged increases.

(b) To show that the offline sales volume decreases, we have to check if $\frac{(\beta \theta-\lambda \gamma)(\alpha+s)+\left(2 \theta-\lambda \gamma^{2}\right)(1-s)}{\theta(4-\beta \gamma)-\lambda \gamma^{2}}<\frac{\beta(\alpha+s)+2(1-s)}{4-\beta \gamma}$, with reference to Eqs. (5 and 23). Suppose the inequality holds. Then, it implies

$$
\begin{array}{r}
{\left[(4-\beta \gamma)(\beta \theta-\lambda \gamma)-\beta\left\{\theta(4-\beta \gamma)-\lambda \gamma^{2}\right\}\right](\alpha+s)<} \\
{\left[2\left\{\theta(4-\beta \gamma)-\lambda \gamma^{2}\right\}-(4-\beta \gamma)\left(2 \theta-\lambda \gamma^{2}\right)\right](1-s)}
\end{array}
$$


Since $1-s>\alpha+s$, it would suffice to show

$$
\begin{aligned}
& (4-\beta \gamma)(\beta \theta-\lambda \gamma) \\
& \quad-\beta\left\{\theta(4-\beta \gamma)-\lambda \gamma^{2}\right\}<2\left\{\theta(4-\beta \gamma)-\lambda \gamma^{2}\right\} \\
& \quad-(4-\beta \gamma)\left(2 \theta-\lambda \gamma^{2}\right)
\end{aligned}
$$

which implies

$$
-2 \lambda \gamma(2-\beta \gamma)<\lambda \gamma^{2}(2-\beta \gamma) \quad \Rightarrow \quad \lambda \gamma(2+\gamma)
$$

$(2-\beta \gamma)>0$ which is true since $\beta, \gamma<1$.

Hence, the inequality holds and the offline sales volume decreases.

To show that total sales (offline and online) increase, we have to check if $\underline{(\beta \theta-\lambda \gamma)(\alpha+s)}$ $+\left(2 \theta-\lambda \gamma^{2}\right)(1-s) \theta \quad(4-\beta \gamma)-\lambda \gamma^{2}$ $+\lambda \frac{\theta[2(\alpha+s)+\gamma(1-s)]}{\theta(4-\beta \gamma)-\lambda \gamma^{2}}>\frac{\beta(\alpha+s)+2(1-s)}{4-\beta \gamma}$, with reference to Eqs. (5), (23) and (24).

Suppose the inequality holds. Then, it implies true since $\lambda>0, \theta>\gamma$ and $0<\beta, \gamma<1$. Therefore, the inequality holds and total sales (offline and online) increase.

(c) To show that the profit increases, we have to check if, with reference to Eqs. (7 and 21-24), the following inequality holds:

$$
\begin{aligned}
& \frac{(\beta \theta+\lambda \gamma)(\alpha+s)+2 \theta(1-s)}{\theta(4-\beta \gamma)-\lambda \gamma^{2}} \\
& \quad \times \frac{(\beta \theta-\lambda \gamma)(\alpha+s)+\left(2 \theta-\lambda \gamma^{2}\right)(1-s)}{\theta(4-\beta \gamma)-\lambda \gamma^{2}} \\
& +\lambda \frac{2(\alpha+s)+\gamma(1-s)}{\theta(4-\beta \gamma)-\lambda \gamma^{2}} \times \frac{\theta[2(\alpha+s)+\gamma(1-s)]}{\theta(4-\beta \gamma)-\lambda \gamma^{2}} \\
& >\frac{[\beta(\alpha+s)+2(1-s)]^{2}}{(4-\beta \gamma)^{2}}
\end{aligned}
$$

Suppose the inequality holds. Then, it implies

$$
\begin{array}{r}
\frac{[(\beta \theta+\lambda \gamma)(\alpha+s)+2 \theta(1-s)]\left[(\beta \theta-\lambda \gamma)(\alpha+s)+\left(2 \theta-\lambda \gamma^{2}\right)(1-s)\right]}{\left[\theta(4-\beta \gamma)-\lambda \gamma^{2}\right]^{2}}+ \\
\lambda \theta \frac{[2(\alpha+s)+\gamma(1-s)]^{2}}{\left[\theta(4-\beta \gamma)-\lambda \gamma^{2}\right]^{2}}>\frac{[\beta(\alpha+s)+2(1-s)]^{2}}{(4-\beta \gamma)^{2}}
\end{array}
$$

$\frac{(\beta \theta-\lambda \gamma+2 \lambda \theta)(\alpha+s)+\left(2 \theta-\lambda \gamma^{2}+\lambda \gamma \theta\right)(1-s)}{\theta(4-\beta \gamma)-\lambda \gamma^{2}} \quad$ Left hand side of the above inequality $=$

$$
\begin{aligned}
> & \frac{\beta(\alpha+s)+2(1-s)}{4-\beta \gamma} \\
\Rightarrow & (\beta \theta-\lambda \gamma+2 \lambda \theta)(4-\beta \gamma)(\alpha+s) \\
+ & \left(2 \theta-\lambda \gamma^{2}+\lambda \gamma \theta\right)(4-\beta \gamma)(1-s) \\
> & \beta\left[\theta(4-\beta \gamma)-\lambda \gamma^{2}\right](\alpha+s) \\
& +2\left[\theta(4-\beta \gamma)-\lambda \gamma^{2}\right](1-s) \\
\Rightarrow & {\left[\left(-\lambda \gamma^{2}+\lambda \gamma \theta\right)(4-\beta \gamma)+2 \lambda \gamma^{2}\right](1-s) } \\
> & {\left[-\lambda \beta \gamma^{2}-(-\lambda \gamma+2 \lambda \theta)(4-\beta \gamma)\right](\alpha+s) }
\end{aligned}
$$

Since $1-s>\alpha+s$, it would suffice to show

$$
\begin{aligned}
& \left(-\lambda \gamma^{2}+\lambda \gamma \theta\right)(4-\beta \gamma)+2 \lambda \gamma^{2}>-\lambda \beta \gamma^{2} \\
& \quad-(-\lambda \gamma+2 \lambda \theta)(4-\beta \gamma)
\end{aligned}
$$

which implies $\lambda[\{\theta(2+\gamma)-\gamma(1+\gamma)\}$ $\left.(4-\beta \gamma)+\gamma^{2}(2+\beta)\right]>0$. This is, however, 


$$
\frac{\left[\beta^{2} \theta^{2}+\lambda\left(4 \theta-\lambda \gamma^{2}\right)\right](\alpha+s)^{2}+\theta\left(4 \theta-\lambda \gamma^{2}\right)(1-s)^{2}+(\beta \theta+\lambda \gamma)\left(4 \theta-\lambda \gamma^{2}\right)(\alpha+s)(1-s)}{\left[\theta(4-\beta \gamma)-\lambda \gamma^{2}\right]^{2}}
$$

Right hand side of the above inequality =

$$
\frac{\beta^{2}(\alpha+s)^{2}+4(1-s)^{2}+4 \beta(\alpha+s)(1-s)}{(4-\beta \gamma)^{2}}
$$

Therefore, rearranging the terms on the left and right hand sides of the above inequality, we get the following:

$$
\begin{array}{r}
{\left[\theta\left(4 \theta-\lambda \gamma^{2}\right)(4-\beta \gamma)^{2}-4\left\{\theta(4-\beta \gamma)-\lambda \gamma^{2}\right\}^{2}\right]} \\
(1-s)^{2}+\left[(\beta \theta+\lambda \gamma)\left(4 \theta-\lambda \gamma^{2}\right)(4-\beta \gamma)^{2}\right. \\
\left.-4 \beta\left\{\theta(4-\beta \gamma)-\lambda \gamma^{2}\right\}^{2}\right](\alpha+s)(1-s) \\
>\left[\beta^{2}\left\{\theta(4-\beta \gamma)-\lambda \gamma^{2}\right\}^{2}-\left\{\beta^{2} \theta^{2}+\lambda\left(4 \theta-\lambda \gamma^{2}\right)\right\}\right. \\
\left.(4-\beta \gamma)^{2}\right](\alpha+s)^{2}
\end{array}
$$

Now, the coefficient of $(\alpha+s)(1-s)$ on the left hand side of the above inequality $=$

$$
\begin{aligned}
& (\beta \theta+\lambda \gamma)\left(4 \theta-\lambda \gamma^{2}\right)(4-\beta \gamma)^{2} \\
& -4 \beta\left\{\theta(4-\beta \gamma)-\lambda \gamma^{2}\right\}^{2} \\
= & {\left[(\beta \theta+\lambda \gamma)\left(4 \theta-\lambda \gamma^{2}\right)-4 \beta \theta^{2}\right] } \\
& (4-\beta \gamma)^{2}+8 \lambda \beta \theta \gamma^{2}(4-\beta \gamma)-4 \lambda^{2} \beta \gamma^{4} \\
= & \lambda \gamma\left[\theta(4-\beta \gamma)-\lambda \gamma^{2}\right](4-\beta \gamma)^{2} \\
& +4 \lambda \beta \gamma^{2}\left[2 \theta(4-\beta \gamma)-\lambda \gamma^{2}\right]
\end{aligned}
$$

Since $0<\lambda, \beta, \gamma<1$ and $\theta>1$, the coefficient of $(\alpha+s)(1-s)$ on the left hand side of the above inequality is positive. Also, since $1-s>\alpha+s$, it would suffice to show

$$
\begin{array}{r}
\theta\left(4 \theta-\lambda \gamma^{2}\right)(4-\beta \gamma)^{2}-4\left[\theta(4-\beta \gamma)-\lambda \gamma^{2}\right]^{2}> \\
\beta^{2}\left[\theta(4-\beta \gamma)-\lambda \gamma^{2}\right]^{2}-\left[\beta^{2} \theta^{2}+\lambda\left(4 \theta-\lambda \gamma^{2}\right)\right](4-\beta \gamma)^{2}
\end{array}
$$

If the above inequality holds, then

$$
\begin{aligned}
& -\lambda \theta \gamma^{2}(4-\beta \gamma)^{2}-4 \lambda^{2} \gamma^{4}+8 \lambda \theta \gamma^{2}(4-\beta \gamma)> \\
& \beta^{2}\left[\lambda^{2} \gamma^{4}-2 \lambda \theta \gamma^{2}(4-\beta \gamma)\right]-\lambda\left(4 \theta-\lambda \gamma^{2}\right)(4-\beta \gamma)^{2} \Rightarrow \\
& \lambda\left[\left\{\theta\left(4-\gamma^{2}\right)-\lambda \gamma^{2}\right\}(4-\beta \gamma)^{2}\right. \\
& \left.\quad+\gamma^{2}\left\{2 \theta(4-\beta \gamma)-\lambda \gamma^{2}\right\}\left(4+\beta^{2}\right)\right]>0
\end{aligned}
$$

Since $0<\lambda, \beta, \gamma<1$ and $\theta>1$, the above inequality holds and hence the profit increases.

\section{Proof of Proposition 10}

(a) Comparing Eqs. (4 and 22), it is straightforward to show that the price charged increases.

(b) To show that the sales volume decreases, we have to check if $(1-\lambda) \frac{\theta[2(\alpha+s)+\gamma(1-s)]}{\theta(4-\beta \gamma)-\lambda \gamma^{2}}<\frac{2(\alpha+s)+\gamma(1-s)}{4-\beta \gamma}$, with reference to Eqs. (6 and 24).

Suppose the inequality holds. Then the above inequality implies

$$
\begin{aligned}
& (1-\lambda) \theta(4-\beta \gamma)<\theta(4-\beta \gamma)-\lambda \gamma^{2} \Rightarrow \\
& \lambda\left[\theta(4-\beta \gamma)-\gamma^{2}\right]>0
\end{aligned}
$$

Since $0<\lambda, \beta, \gamma<1$ and $\theta>1$, the above inequality holds and hence the sales volume decreases.

(c) To show that the profit decreases, we have to check

$(1-\lambda) \theta \frac{[2(\alpha+s)+\gamma(1-s)]^{2}}{\left[\theta(4-\beta \gamma)-\lambda \gamma^{2}\right]^{2}}<\frac{[2(\alpha+s)+\gamma(1-s)]^{2}}{\theta(4-\beta \gamma)^{2}}, \quad$ with reference to Eqs. (8, 22 and 24).

Suppose the inequality holds. Then, it implies

$$
\begin{array}{r}
(1-\lambda) \theta^{2}(4-\beta \gamma)^{2}<\left[\theta(4-\beta \gamma)-\lambda \gamma^{2}\right]^{2} \Rightarrow \\
\lambda\left[\theta(4-\beta \gamma)\left\{\theta(4-\beta \gamma)-2 \gamma^{2}\right\}+\lambda \gamma^{4}\right]>0
\end{array}
$$

Since $0<\lambda, \beta, \gamma<1$ and $\theta>1$, the above inequality holds and hence the profit decreases.

\section{Proof of Proposition 11}

(a) The proof is straightforward by comparing Eqs. (6 and 24). 
(b) To prove, we have to show, with reference to Eqs. (5, 6, 23 and 24)

$$
\begin{gathered}
\frac{(\beta \theta-\lambda \gamma+2 \theta)(\alpha+s)+\left(2 \theta-\lambda \gamma^{2}+\gamma \theta\right)(1-s)}{\theta(4-\beta \gamma)-\lambda \gamma^{2}} \\
<\frac{(2+\beta)(\alpha+s)+(2+\gamma)(1-s)}{4-\beta \gamma}
\end{gathered}
$$

Suppose the inequality holds. Then, it implies

$$
\begin{aligned}
& {[(2+\beta) \theta-\lambda \gamma](4-\beta \gamma)(\alpha+s)} \\
& \quad+\left[(2+\gamma) \theta-\lambda \gamma^{2}\right](4-\beta \gamma)(1-s)< \\
& {\left[\theta(4-\beta \gamma)-\lambda \gamma^{2}\right][(2+\beta)(\alpha+s)+(2+\gamma)(1-s)] \Rightarrow} \\
& \lambda \gamma[2 \gamma(1+\beta)-4](\alpha+s)<\lambda \gamma^{2}[2-\gamma(1+\beta)](1-s)
\end{aligned}
$$

Since $1-s>\alpha+s$, it would suffice to show $\lambda \gamma[2 \gamma(1+\beta)-4]<\lambda \gamma^{2}[2-\gamma(1+\beta)]$ which implies $\lambda \gamma\left[4-2 \beta \gamma-\gamma^{2}(1+\beta)\right]>0$.

Since $0<\lambda, \beta, \gamma<1$, the above inequality holds and hence it proves that total offline and online sales decrease.

\section{Proof of Proposition 12}

(a) By comparing Eqs. (3 and 25), it is straightforward to show that the price charged by the traditional retailer increases. To show that the price charged by the online retailer also increases, we have to prove the following, with reference to Eqs. (4 and 26):

$$
\begin{gathered}
\frac{(4-\beta \gamma)(\alpha+s)+2 \gamma(1-s)}{4 \theta(2-\beta \gamma)} \\
>\frac{2(\alpha+s)+\gamma(1-s)}{\theta(4-\beta \gamma)}
\end{gathered}
$$

Supposing the above inequality is true, it can be rearranged to write the following:

$$
\begin{aligned}
& {[2 \gamma(4-\beta \gamma)-4 \gamma(2-\beta \gamma)](1-s)} \\
& \quad>\left[8(2-\beta \gamma)-(4-\beta \gamma)^{2}\right](\alpha+s)
\end{aligned}
$$

Since $1-s>\alpha+s$, it would suffice to show $2 \gamma$ $(4-\beta \gamma)-4 \gamma(2-\beta \gamma)>8(2-\beta \gamma)-(4-$ $\beta \gamma)^{2}$ which implies $2 \beta \gamma^{2}>-\beta^{2} \gamma^{2}$.

However, the above is true, and hence, it shows that the price charged by the online retailer increases.

By comparing Eqs. (5 and 27), it can be easily shown that offline sales decrease. To show that online sales increase, we have to prove the following, with reference to Eqs. (6 and 28):

$$
\begin{gathered}
\frac{(4-\beta \gamma)(\alpha+s)+2 \gamma(1-s)}{4(2-\beta \gamma)} \\
>\frac{2(\alpha+s)+\gamma(1-s)}{4-\beta \gamma}
\end{gathered}
$$

However, it is already shown in part (a) that the above inequality holds. Hence, it follows that online sales increase.

(c) A comparison of Eqs. (7 and 29) shows that the profit of the traditional retailer increases. To show that the profit of the online retailer also increases, the following must hold, with reference to Eqs. (8 and 30):

$$
\begin{gathered}
\frac{[(4-\beta \gamma)(\alpha+s)+2 \gamma(1-s)]^{2}}{\theta[4(2-\beta \gamma)]^{2}} \\
>\frac{[2(\alpha+s)+\gamma(1-s)]^{2}}{\theta(4-\beta \gamma)^{2}}
\end{gathered}
$$

The proof follows part (a). Also, since the price charged by the online retailer and online sales increase, it is intuitively true that the profit of the online retailer increases.

(d) The expression for total offline and online sales is the following, with reference to Eqs. (27 and 28):

$$
\begin{aligned}
q_{1}+ & q_{2}=\frac{\beta(\alpha+s)+2(1-s)}{4}+\frac{(4-\beta \gamma)(\alpha+s)+2 \gamma(1-s)}{4(2-\beta \gamma)} \\
& =\frac{[\beta(2-\beta \gamma)+4-\beta \gamma](\alpha+s)+[2(2-\beta \gamma)+2 \gamma](1-s)}{4(2-\beta \gamma)}
\end{aligned}
$$


To show that total offline and online sales decrease, we have to show the following, with reference to Eqs. (5 and 6):

$$
\begin{aligned}
& \frac{[\beta(2-\beta \gamma)+4-\beta \gamma](\alpha+s)+[2(2-\beta \gamma)+2 \gamma](1-s)}{4(2-\beta \gamma)} \\
& <\frac{(2+\beta)(\alpha+s)+(2+\gamma)(1-s)}{4-\beta \gamma}
\end{aligned}
$$

Rearranging the above inequality, we can write the following:

$$
\begin{aligned}
& {[\{\beta(2-\beta \gamma)+4-\beta \gamma\}(4-\beta \gamma)} \\
& \quad-4(2-\beta \gamma)(2+\beta)](\alpha+s)< \\
& {[4(2-\beta \gamma)(2+\gamma)-\{2(2-\beta \gamma)+2 \gamma\}(4-\beta \gamma)](1-s)}
\end{aligned}
$$

which upon simplification gives

$$
-\beta^{2} \gamma(2-\gamma-\beta \gamma)(\alpha+s)<2 \beta \gamma(2-\gamma-\beta \gamma)(1-s)
$$

Now, since $0<\beta, \gamma<1,2-\gamma-\beta \gamma>0$. Also, $1-s>\alpha+s$. Therefore, the above inequality holds and it follows that total offline and online sales decrease.

\section{Proof of Proposition 13}

(a) While it is straightforward to show that the price charged by the online retailer increases by comparing Eqs. (4 and 31), to show that the price charged by the traditional retailer also increases, we have to show that the following inequality holds, with reference to Eqs. (3 and 32):

$$
\begin{gathered}
\frac{2 \beta(\alpha+s)+(4-\beta \gamma)(1-s)}{4(2-\beta \gamma)} \\
>\frac{\beta(\alpha+s)+2(1-s)}{4-\beta \gamma}
\end{gathered}
$$

Suppose the above inequality holds. Then, rearranging the terms, we may write

$$
\begin{aligned}
& {\left[(4-\beta \gamma)^{2}-8(2-\beta \gamma)\right](1-s)} \\
& \quad>[4 \beta(2-\beta \gamma)-2 \beta(4-\beta \gamma)](\alpha+s)
\end{aligned}
$$

which upon simplification gives

$\beta^{2} \gamma^{2}(1-s)>-2 \beta^{2} \gamma(\alpha+s)$

However, since $1-s>\alpha+s$, the above inequality holds, and hence, the price charged by the traditional retailer increases.

(b) While it is easy to show that online sales decrease by comparing Eqs. (6 and 34), to show that offline sales increase, we have to show the following, with reference to Eqs. (5 and 33):

$$
\begin{gathered}
\frac{2 \beta(\alpha+s)+(4-\beta \gamma)(1-s)}{4(2-\beta \gamma)} \\
>\frac{\beta(\alpha+s)+2(1-s)}{4-\beta \gamma}
\end{gathered}
$$

However, in part (a), it is shown that the above inequality holds. Hence, offline sales increase.

(c) Since both the price charged by the traditional retailer and offline sales increase, the profit of the traditional retailer increases. To show that the profit of the online retailer also increases, we have to compare Eqs. (8 and 36). Since the denominator of Eq. (8) is larger than the denominator of Eq. (36), while their numerators are the same, it is intuitive that the profit of the online retailer increases.

(d) Total offline and online sales can be obtained from Eqs. (33 and 34) as follows:

$$
\begin{aligned}
q_{1} & +q_{2}=\frac{2 \beta(\alpha+s)+(4-\beta \gamma)(1-s)}{4(2-\beta \gamma)} \\
& +\frac{2(\alpha+s)+\gamma(1-s)}{4} \\
& =\frac{[2 \beta+2(2-\beta \gamma)](\alpha+s)+[4-\beta \gamma+\gamma(2-\beta \gamma)](1-s)}{4(2-\beta \gamma)}
\end{aligned}
$$

If total offline and online sales decrease, the following inequality must hold, with reference to Eqs. (5 and 6):

$$
\begin{gathered}
\frac{[2 \beta+2(2-\beta \gamma)](\alpha+s)+[4-\beta \gamma+\gamma(2-\beta \gamma)](1-s)}{4(2-\beta \gamma)} \\
\quad<\frac{(2+\beta)(\alpha+s)+(2+\gamma)(1-s)}{4-\beta \gamma}
\end{gathered}
$$

Supposing the above inequality holds, rearranging the terms, we may write

$$
\begin{gathered}
{[\{2 \beta+2(2-\beta \gamma)\}(4-\beta \gamma)-4(2-\beta \gamma)(2+\beta)](\alpha+s)<} \\
{[4(2-\beta \gamma)(2+\gamma)-\{4-\beta \gamma+\gamma(2-\beta \gamma)\}(4-\beta \gamma)](1-s)}
\end{gathered}
$$

which upon simplification gives

$$
-2 \beta \gamma(2-\beta-\beta \gamma)(\alpha+s)<\beta \gamma^{2}(2-\beta-\beta \gamma)(1-s)
$$


Now, since $0<\beta, \gamma<1,2-\beta-\beta \gamma>0$. Also, $1-s>\alpha+s$. Therefore, the above inequality holds and it follows that total offline and online sales decrease.

\section{Proof of Proposition 14}

(a) Since in Propositions (13) and (14), it is shown that the price of the traditional retailer increases under sequential moves, it is evident that $p_{1}^{\text {Sim }}$ will be the lowest. To show $p_{1}^{\operatorname{Seq}(T R=L)}>p_{1}^{\operatorname{Seq}(\mathrm{OR}=L)}$, we have to prove the following inequality, with reference to Eqs. (25 and 32):

$$
\begin{aligned}
& \frac{\beta(\alpha+s)+2(1-s)}{2(2-\beta \gamma)} \\
& >\frac{2 \beta(\alpha+s)+(4-\beta \gamma)(1-s)}{4(2-\beta \gamma)}
\end{aligned}
$$

It can be easily shown that the above inequality holds by rearranging the terms. Hence, the proposition holds.

(b) While Proposition (13) shows that offline sales decrease, Proposition (14) shows that offline sales increase. Hence, the proof is straightforward.

(c) Propositions (13) and (14) show that the profit of the traditional retailer increases under sequential moves. Therefore, it is evident that $\Pi_{1}^{\text {Sim }}$ will be the lowest. To show $\Pi_{1}^{S e q(O R=L)}>\Pi_{1}^{S e q(T R=L)}$, we have to prove the following inequality, with reference to Eqs. (29 and 35):

$$
\begin{gathered}
\frac{[2 \beta(\alpha+s)+(4-\beta \gamma)(1-s)]^{2}}{[4(2-\beta \gamma)]^{2}} \\
>\frac{[\beta(\alpha+s)+2(1-s)]^{2}}{8(2-\beta \gamma)}
\end{gathered}
$$

Supposing the inequality holds, the following is obtained upon simplification:

$\beta^{2} \gamma^{2}(1-s)^{2}+\quad 4 \beta^{2} \gamma(\alpha+s)(1-s)+2 \beta^{3} \gamma$ $(\alpha+s)^{2}>0$ which is true.

Therefore, the inequality holds, and hence the proof.

(d) Since Propositions (13) and (14) show that the price of the online retailer increases under sequential moves, it is clear that $p_{2}^{\text {Sim }}$ will be the lowest. To prove $p_{2}^{\operatorname{Seq}(O R=L)}>p_{2}^{\operatorname{Seq}(T R=L)}$, we have to show that the following inequality holds, with reference to Eqs. (26 and 31):

$$
\begin{aligned}
& \frac{2(\alpha+s)+\gamma(1-s)}{2 \theta(2-\beta \gamma)} \\
& >\frac{(4-\beta \gamma)(\alpha+s)+2 \gamma(1-s)}{4 \theta(2-\beta \gamma)}
\end{aligned}
$$

It can be easily shown that the above inequality holds, and hence, the proof.

(e) Since Proposition (13) shows that online sales increase and Proposition (14) shows that online sales decrease, the proof is straightforward.

(f) Propositions (13) and (14) show that the profit of the online retailer increases under sequential moves. Hence, $\Pi_{2}^{\text {Sim }}$ will be the lowest. To show $\Pi_{2}^{S e q(T R=L)}>\Pi_{2}^{\text {Seq }(O R=L)}$, we have to prove the following inequality, with reference to Eqs. (30 and 36):

$$
\begin{gathered}
\frac{[(4-\beta \gamma)(\alpha+s)+2 \gamma(1-s)]^{2}}{\theta[4(2-\beta \gamma)]^{2}} \\
>\frac{[2(\alpha+s)+\gamma(1-s)]^{2}}{8 \theta(2-\beta \gamma)}
\end{gathered}
$$

Supposing the above inequality holds, it gives the following upon simplification:

$2 \beta \gamma^{3}(1-s)^{2}+4 \beta \gamma^{2}(\alpha+s)(1-s)+\beta^{2} \gamma^{2}(\alpha$ $+s)^{2}>0$ which is true.

Therefore, the inequality holds, and hence the proof.

(g) Since Propositions (13) and (14) show that total offline and online sales decrease under sequential moves, it is clear that $\left(q_{1}+q_{2}\right)^{\text {Sim }}$ will be the highest. To prove $\left(q_{1}+q_{2}\right)^{\operatorname{Seq}(\text { OR=L) }}$ $>\left(q_{1}+q_{2}\right)^{\operatorname{Seq}(T R=L)}$, we have to compare the expressions for total offline and online sales derived in part (d) of Propositions (13) and (14), and show the following:

$$
\begin{aligned}
& \frac{[2 \beta+2(2-\beta \gamma)](\alpha+s)+[4-\beta \gamma+\gamma(2-\beta \gamma)](1-s)}{4(2-\beta \gamma)}> \\
& \frac{[\beta(2-\beta \gamma)+4-\beta \gamma](\alpha+s)+[2(2-\beta \gamma)+2 \gamma](1-s)}{4(2-\beta \gamma)}
\end{aligned}
$$

which upon simplification gives 
$\beta \gamma(1-\gamma)(1-s)>\beta \gamma(1-\beta)(\alpha+s)$

However, the above inequality is true given $0<\beta, \gamma<1, \beta>\gamma$ and $1-s>\alpha+s$. Hence, the proof.

\section{Appendix 2}

See Figs. 1, 2, 3, 4, 5, 6, 7, 8, 9, 10, 11, 12, 13, 14, 15, $16,17,18$

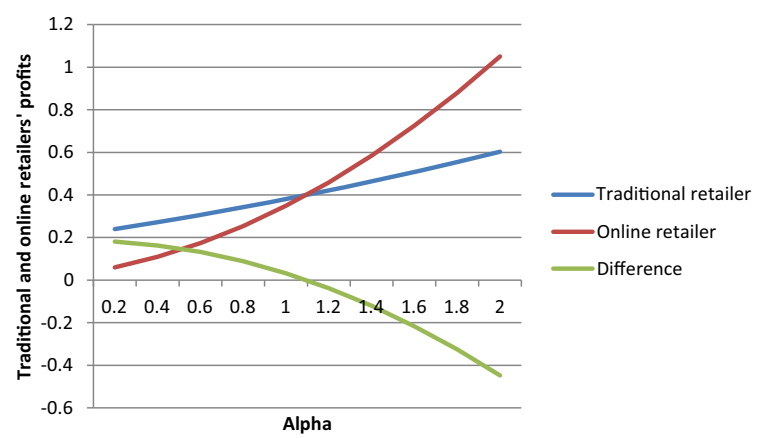

Fig. 1 Traditional and online retailers' profits versus $\alpha$ with $\beta=0.6, \gamma=0.4, \theta=1.5$ and $s=0.2$ (base case)

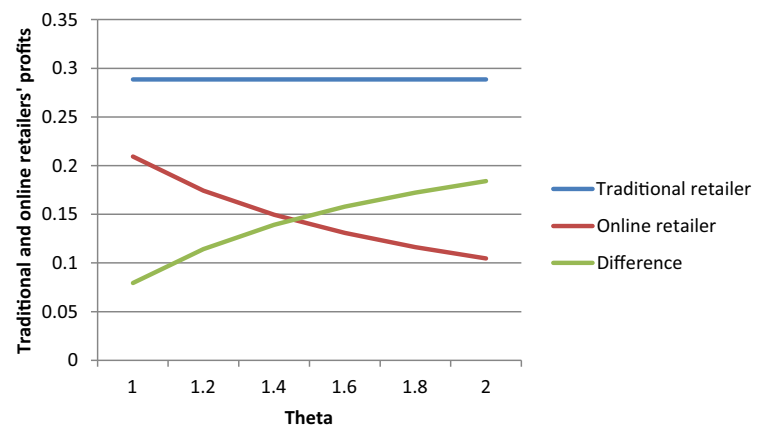

Fig. 2 Traditional and online retailers' profits versus $\theta$ with $\alpha=0.5, \beta=0.6, \gamma=0.4$ and $s=0.2$ (base case)

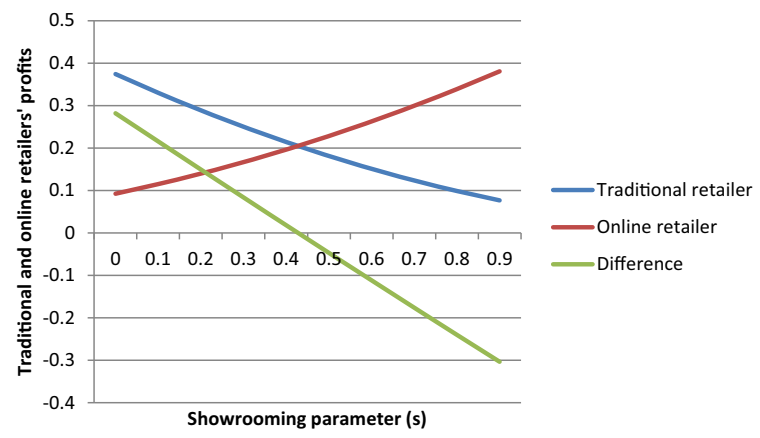

Fig. 3 Traditional and online retailers' profits versus showrooming parameter $(s)$ with $\alpha=0.5, \beta=0.6, \gamma=0.4$ and $\theta=1.5$ (base case)

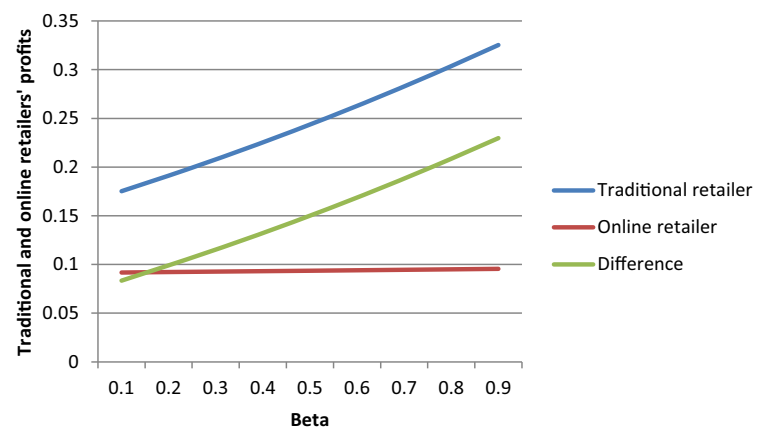

Fig. 4 Traditional and online retailers' profits versus $\beta$ with $\alpha=0.5, \gamma=0.1, \theta=1.5$ and $s=0.2$ (base case)

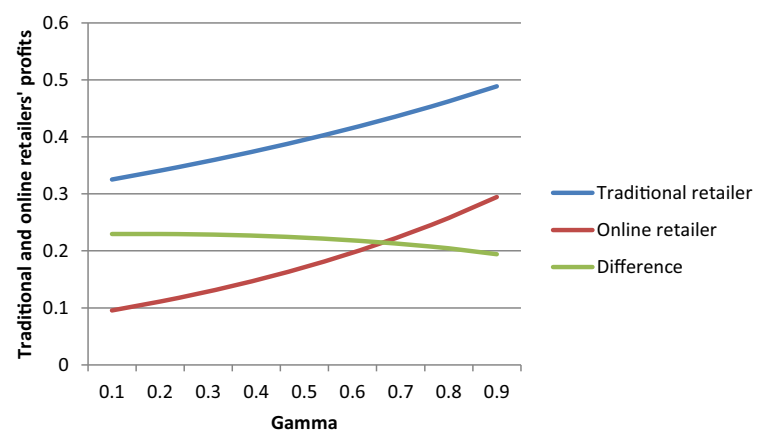

Fig. 5 Traditional and online retailers' profits versus $\gamma$ with $\alpha=0.5, \beta=0.9, \theta=1.5$ and $s=0.2$ (base case) 


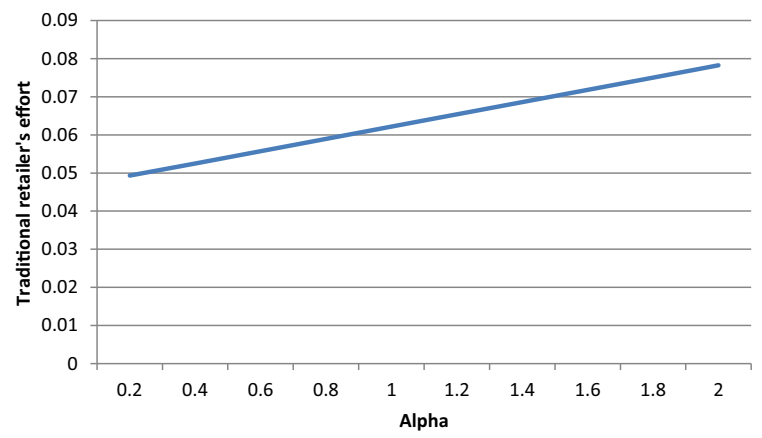

Fig. 6 Traditional retailer's effort to counter showrooming versus $\alpha$ with $\beta=0.6, \gamma=0.4, \theta=1.5$ and $s=0.2$

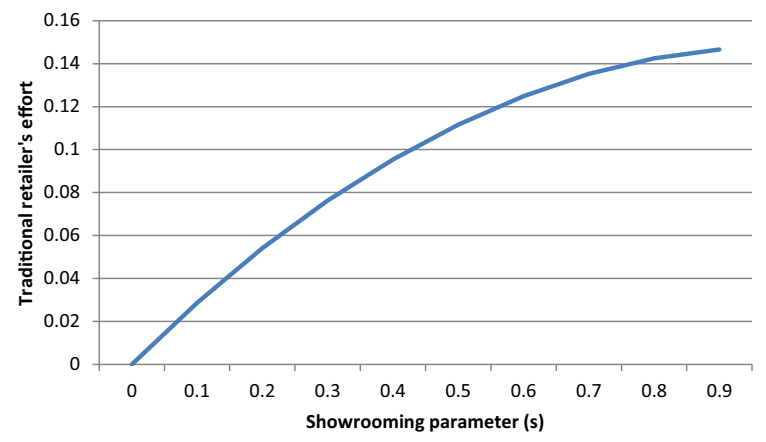

Fig. 7 Traditional retailer's effort to counter showrooming versus showrooming parameter $(s)$ with $\alpha=0.5, \beta=0.6$, $\gamma=0.4$ and $\theta=1.5$

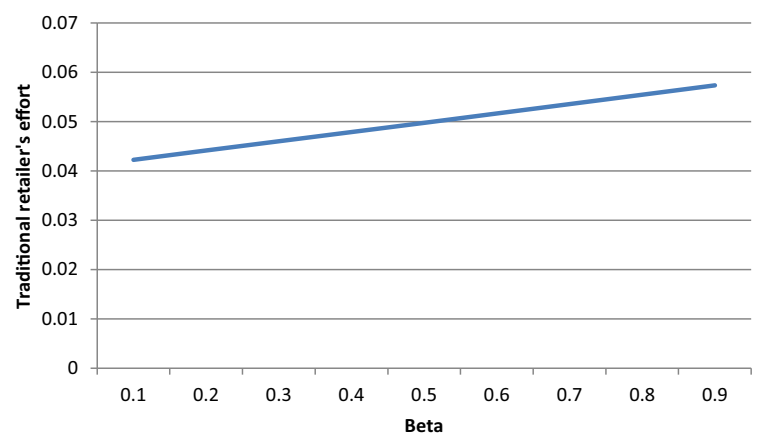

Fig. 8 Traditional retailer's effort to counter showrooming versus $\beta$ with $\alpha=0.5, \gamma=0.1, \theta=1.5$ and $s=0.2$

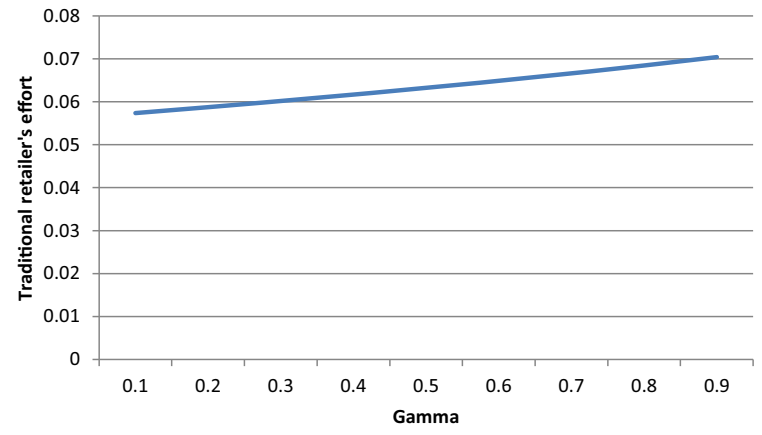

Fig. 9 Traditional retailer's effort to counter showrooming versus $\gamma$ with $\alpha=0.5, \beta=0.9, \theta=1.5$ and $s=0.2$

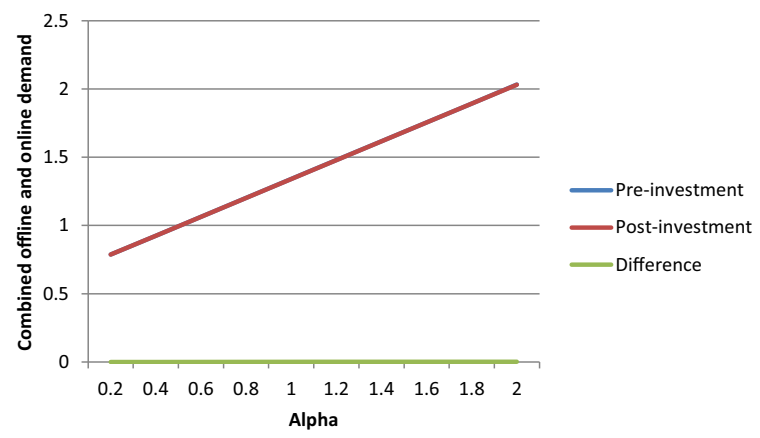

Fig. 10 Combined offline and online demand, pre- and postinvestment by the traditional retailer, versus $\alpha$ with $\beta=0.6$, $\gamma=0.4, \theta=1.5$ and $s=0.2$

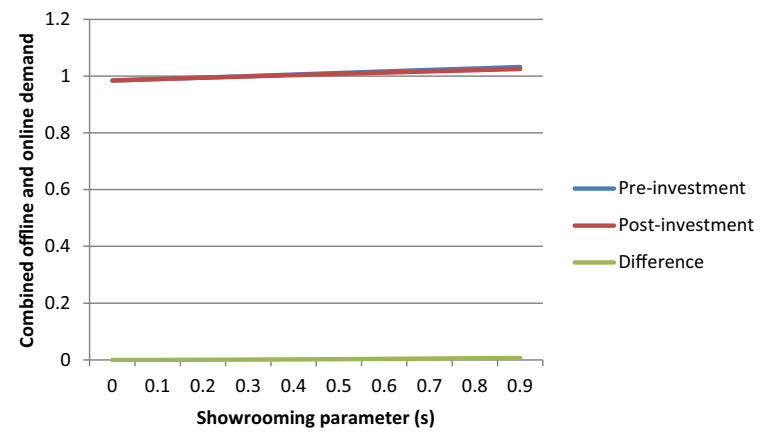

Fig. 11 Combined offline and online demand, pre- and postinvestment by the traditional retailer, versus showrooming parameter $(s)$ with $\alpha=0.5, \beta=0.6, \gamma=0.4$ and $\theta=1.5$ 


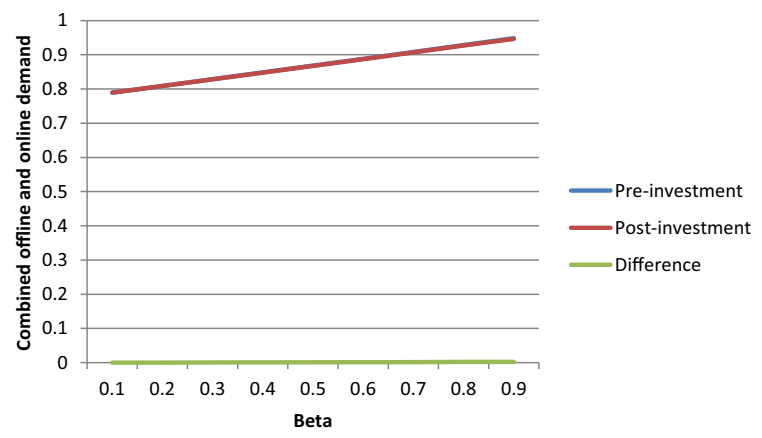

Fig. 12 Combined offline and online demand, pre- and postinvestment by the traditional retailer, versus $\beta$ with $\alpha=0.5$, $\gamma=0.1, \theta=1.5$ and $s=0.2$

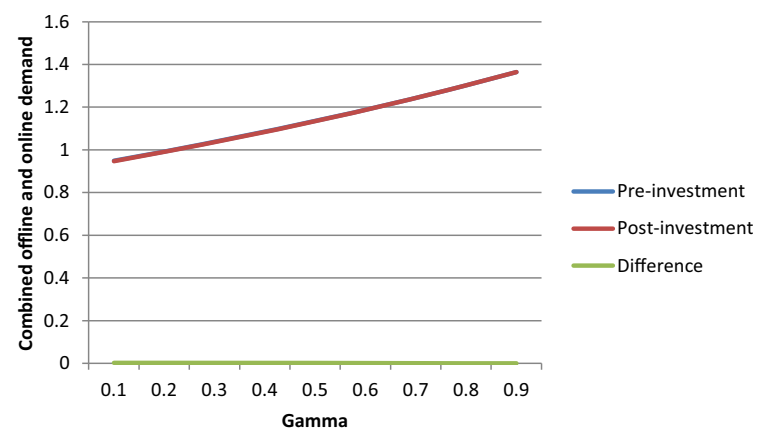

Fig. 13 Combined offline and online demand, pre- and postinvestment by the traditional retailer, versus $\gamma$ with $\alpha=0.5$, $\beta=0.9, \theta=1.5$ and $s=0.2$

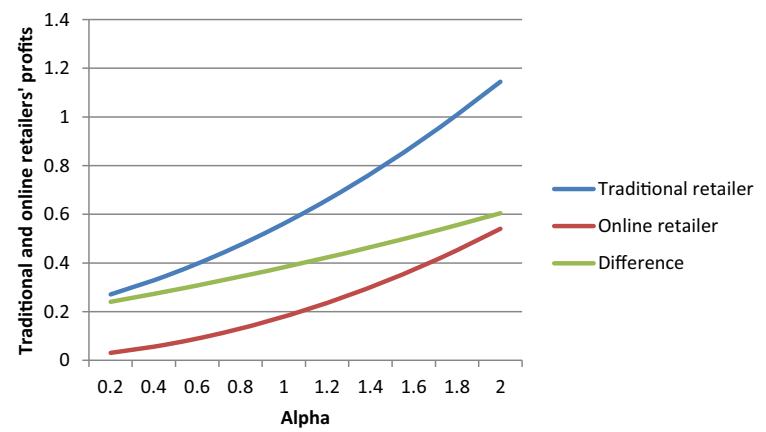

Fig. 14 Traditional and online retailers' profits, post-online entry by the traditional retailer, versus $\alpha$ with $\beta=0.6, \gamma=0.4$, $\theta=1.5, \lambda=0.5$ and $s=0.2$

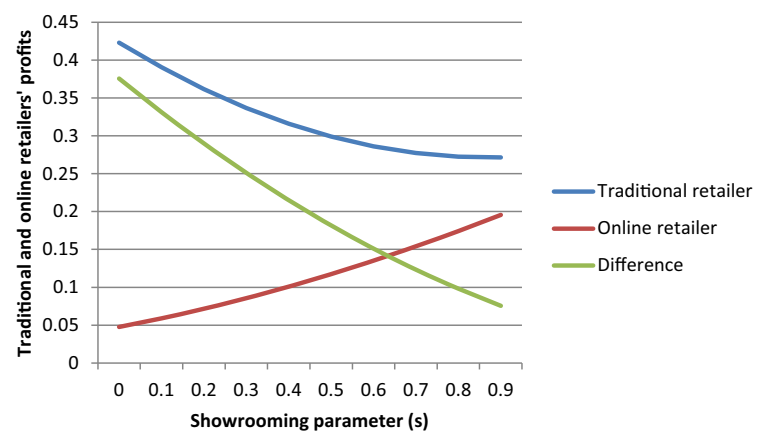

Fig. 15 Traditional and online retailers' profits, post-online entry by the traditional retailer, versus showrooming parameter (s) with $\alpha=0.5, \beta=0.6, \gamma=0.4$ and $\theta=1.5$ and $\lambda=0.5$

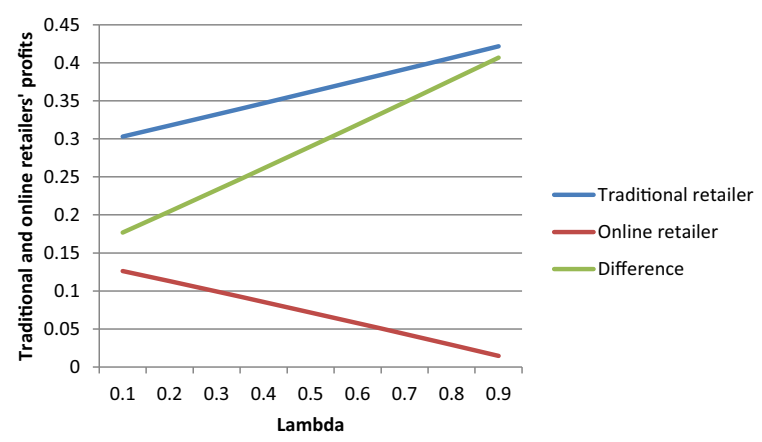

Fig. 16 Traditional and online retailers' profits, post-online entry by the traditional retailer, versus $\lambda$ with $\alpha=0.5, \beta=0.6$, $\gamma=0.4, \theta=1.5$ and $s=0.2$

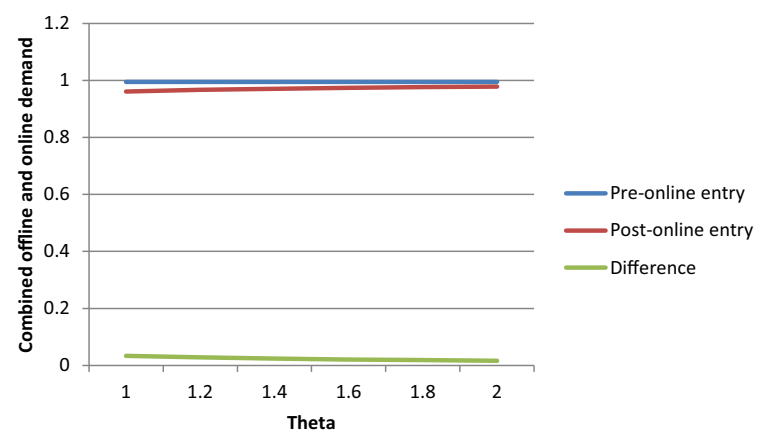

Fig. 17 Combined offline and online demand, pre- and postonline entry by the traditional retailer, versus $\theta$ with $\alpha=0.5$, $\beta=0.6, \gamma=0.4, \lambda=0.5$ and $s=0.2$ 


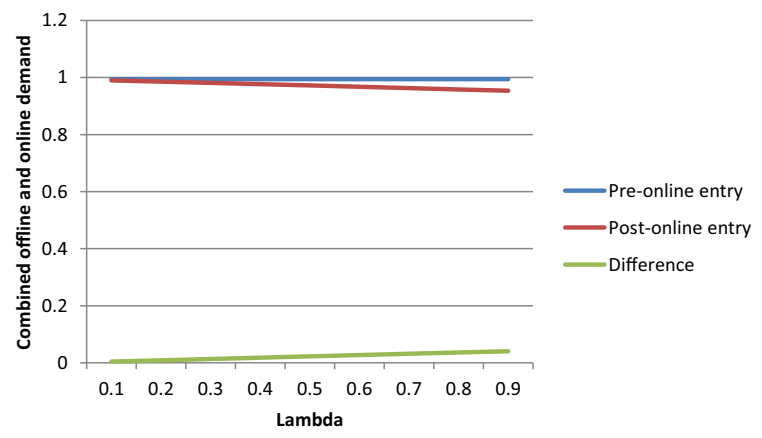

Fig. 18 Combined offline and online demand, pre- and postonline entry by the traditional retailer, versus $\lambda$ with $\alpha=0.5$, $\beta=0.6, \gamma=0.4, \theta=1.5$, and $s=0.2$

\section{References}

Abhishek K, Jerath K, Zhang ZJ (2016) Agency selling or reselling? Channel structures in electronic retailing. Manage Sci 62(8):2259-2280

Agatz NAH, Fleischmann M, van Nunen JAEE (2008) E-fulfillment and multi-channel distribution: a review. Eur $\mathbf{J}$ Oper Res 187:339-356

Balakrishnan A, Sundaresan S, Zhang B (2014) Browse-andswitch: retail-online competition under value uncertainty. Prod Oper Manag 23(7):1129-1145

Basak S, Basu P, Avittathur B, Sikdar S (2017) A game theoretic analysis of multichannel retail in the context of 'Showrooming.' Decis Support Syst 103:34-45

Basak S, Basu P, Avittathur B, Sikdar S (2020) Manufacturer driven strategic coordination as a response to 'Showrooming.' Decis Supp Syst. https://doi.org/10.1016/j.dss. 2020.113305

Bell DR, Gallino S, Moreno A (2014) How to win in an omnichannel world. MIT Sloan Manag Rev 56(1):45-53

Bell DR, Gallino S, Moreno A (2018) Offline showrooms in omnichannel retail: demand and operational benefits. Manage Sci 64(4):1629-1651

Bernstein F, Song J-S, Zheng S (2008) 'Bricks-and-Mortar vs. 'Clicks-and-Mortar': an equilibrium analysis. Eur J Oper Res 187:671-690

Brynjolfsson E, Smith MD (2000) Frictionless commerce? A comparison of internet and conventional retailers. Manage Sci 46(4):563-585

Brynjolfsson E, Hu Y, Rahman MS (2009) Battle of the retail channels: how product selection and geography drive cross-channel competition. Manage Sci 55(11):1755-1765

Brynjolfsson E, Hu YJ, Rahman MS (2013) Competing in the age of omnichannel retailing. MIT Sloan Manag Rev 54(4):23-29

Cattani K, Gilland W, Heese HS, Swaminathan J (2006) Boiling frogs: pricing strategies for a manufacturer adding a direct channel that competes with the traditional channel. Prod Oper Manag 15(1):40-56

Chai L, Wu DD, Dolgui A, Duan Y (2021) Pricing Strategy for B\&M store in a dual-channel supply chain based on hotelling model. Int J Prod Res 59(18):5578-5591
Chen Y, Cheung CMK, Tan C-W (2018) Omnichannel business research: opportunities and challenges. Decis Supp Syst 109:1-4

Dahana WD, Shin H, Katsumata S (2018) Influence of individual characteristics on whether and how much consumers engage in showrooming behaviour. Electron Commer Res 18:665-692

Darlington H (2019) Showroom strategies: big changes on the horizon. Supp House times 61(11):64-65

Fassnacht M, Beatty SE, Szajna M (2019) Combating the negative effects of showrooming: successful salesperson tactics for converting showroomers into buyers. J Bus Res 102:131-139

Feng L, Li Y, Xu F, Deng Q (2019) Optimal pricing and trade-in policies in a dual-channel supply chain when considering market segmentation. Int J Prod Res 57(9):2828-2846

Flavian C, Gurrea R, Orus C (2020) Combining channels to make smart purchases: the role of webrooming and showrooming. Jf Retail Consum Serv. https://doi.org/10. 1016/j.jretconser.2019.101923

Frasquet M, Miquel-Romero MJ (2021) Competitive (versus Loyal) showrooming: an application of the push-pullmooring framework. J Retail Consum Serv. https://doi.org/ 10.1016/j.jretconser.2021.102639

Freeman M (2014) Showrooming: it's an opportunity for retail, not a Threat, The Guardian, January 15, Available at https:// www.theguardian.com/media-network/media-network-blog/ 2014/jan/15/showrooming-opportunity-retail-threat, Last accessed on October 10, 2021

Gal-Or E (1985) First mover and second mover advantages. Int Econ Rev 26(3):649-653

Gao F, Su X (2017) Online and offline information for omnichannel retailing. Manuf Serv Oper Manag 19(1):84-98

Gensler S, Neslin SA, Verhoef PC (2017) The showrooming phenomenon: it's more than just about price. J Interact Mark 38:29-43

Goodfellow P (2012) The showroom showdown: best buy versus amazon, Forbes, August 14, Available at https://www. forbes.com/sites/prospernow/2012/08/14/the-showroomshowdown-best-buy-vs-amazon/\#75e5cefb65d9, Last accessed on October 10, 2021

Gupta VK, Ting QU, Tiwari MK (2019) Multi-period price optimization problem for omnichannel retailers accounting for customer heterogeneity. Int J Prod Econ 212:155-167

He Y, Xu Q, Wu P (2020) Omnichannel retail operations with refurbished consumer returns. Int $\mathrm{J}$ Prod Res 58(1):271-290

Jing B (2018) Showrooming and webrooming: information externalities between online and offline sellers. Mark Sci 37(3):469-483

Johnson O, Ramirez SA (2021) The influence of showrooming on millennial generational cohorts online shopping behaviour. Int J Retail Distrib Manag 49(1):81-103

Kesteloo M and Hoogenberg M (2013) Footprint 2020: offline retail in an online world, strategy\&, available at https:// www.strategyand.pwc.com/nl/en/reports/strategyand-foot print-2020.pdf, Last accessed on October 10, 2021

KPMG (2017) The truth about online consumers: 2017 Global Online Consumer Report, Available at https://assets.kpmg/ 
content $/ \mathrm{dam} / \mathrm{kpmg} / \mathrm{xx} / \mathrm{pdf} / 2017 / 01 /$ the-truth-about-onlineconsumers.pdf, Last accessed on October 10, 2021

Kuksov D, Liao C (2018) “When showrooming increases retailer profit. J Market Res LV:459-473

Li Z, Lu Q, Talebian M (2015) Online versus bricks-and-mortar retailing: a comparison of price, assortment and delivery time. Int J Prod Res 53(13):3823-3835

Li G, Li L, Sun J (2019) Pricing and service effort strategy in a dual-channel supply chain with showrooming effect. Transp Res Part E 126:32-48

Li G, Zhang T, Tayi GK (2020) Inroad to omni-channel retailing: physical showroom deployment of an online retailer. Eur J Oper Res 283:676-691

Li Y, Li B, Zheng W, Chen X (2021) "Reveal or Hide? Impact of demonstration on pricing decisions considering showrooming behaviour. Omega. https://doi.org/10.1016/j. omega.2020.102329

Liu Z, Lu L, Qi X (2020) The showrooming effect on integrated dual channels. J Op Res Soc 71(9):1347-1356

Mehra A, Kumar S, Raju JS (2018) Competitive strategies for brick-and-mortar stores to counter 'Showrooming.' Manage Sci 64(7):3076-3090

Mohammed R (2015) How walmart can start competing online, Harvard Business Review, October 21, pp. 2-4

Moran C (2013) Stores Combat Showrooming with \$5 'Just Looking' Fee, Consumerist, March 25, Available at https:// consumerist.com/2013/03/25/store-combats-showroomingwith-5-just-looking-fee/, Last accessed on October 10, 2021

Ofek E, Katona Z, Sarvary M (2011) 'Bricks and clicks': the impact of product returns on the strategies of multichannel retailers. Mark Sci 30(1):42-60

Quint M, Rogers D and Ferguson R (2013) "Showrooming and the Rise of the Mobile-assisted Shopper", Columbia Business School and AIMIA Report, September, Available at https://www8.gsb.columbia.edu/globalbrands/sites/globa lbrands/files/images/Showrooming_Rise_Mobile_Assisted_ Shopper_Columbia-Aimia_Sept2013.pdf, Last accessed on October 10, 2021

Radhi M, Zhang G (2019) Optimal cross-channel return policy in dual-channel retailing systems. Int $\mathrm{J}$ Prod Econ 210:184-198

Raj SP, Rhee B-D, Sivakumar K (2020) Manufacturer adoption of a unilateral pricing policy in a multi-channel setting to combat customer showrooming. J Bus Res 110:104-118

Rajkumar N, Vishwakarma P, Gangwani KK (2021) Investigating consumers' Path to Showrooming: a perceived value-based perspective. Int J Retail Distrib Manag 49(2):299-316

Rapp A, Baker TL, Bachrach DG, Ogilvie J, Beitelspacher LS (2015) Perceived customer showrooming behaviour and the effect on retail salesperson self-efficacy and performance. J Retail 91(2):358-369

Rejon-Guardia F, Luna-Nevarez C (2017) Showrooming in consumer electronics retailing: an empirical study. J Internet Commer 16(2):174-201

Sahu KC, Khan MN, Das Gupta K (2021) Determinants of webrooming and showrooming behaviour: a systematic literature review. J Internet Commer 20(2):137-166

Sawhney M, Goodman P and Keerthivasan G (2017) Best buy: creating a winning customer experience in consumer electronics, Kellogg School of Management Case \# KE1023, October, pp. 1-18

Schneider PJ, Zielke S (2021) Price versus service: can retailers beat showrooming with competence. J Retail Consum Serv. https://doi.org/10.1016/j.jretconser.2021.102592

Shankar A, Gupta M, Tiwari AK, Behl A (2021) How does convenience impact showrooming intention? Omnichannel retail strategies to manage global retail apocalypse. J Strat Market. https://doi.org/10.1080/0965254X.2021.1965189 ,LastaccessedonOctober10

Shi M, Zhou J, Jiang Z (2019) Consumer heterogeneity and online vs. offline retail spatial competition. Front Bus Res China. https://doi.org/10.1186/s11782-019-0059-9.pdf

Shin J (2007) How does free riding on customer service affect competition? Mark Sci 26(4):488-503

Sit JK, Hoang A, Inversini A (2018) Showrooming and retail opportunities: a qualitative investigation via a consumerexperience lens. J Retail Consum Serv 40:163-174

Sopadjieva E, Dholakia UM and Benjamin B (2017) A study of 46,000 shoppers shows that omnichannel retailing works, Harvard Business Review, January 3, pp. 2-4

Statista (2020) Online vs. offline purchases by category in the U.S. 2020 Available at https://www.statista.com/forecasts/ 997092/online-vs-offline-purchases-by-category-in-the-us \#statisticContainer, Last accessed on October 10, 2021

Teixeira TS, Gupta S (2015) Case study: can you win back online shoppers? Harvard Bus Rev 93(9):117-121

Tsay AA, Agrawal N (2004) Channel conflict and coordination in the E-commerce age. Prod Oper Manag 13(1):93-110

U.S. Census Bureau News (2020) Quarterly retail E-commerce sales: 2nd quarter 2020, August 18, U.S. Department of Commerce, Washington, D.C. 20233, Available at https:// www.census.gov/retail/mrts/www/data/pdf/ec_current.pdf, Last accessed on October 10, 2021

Viejo-Fernandez N, Sanzo-Perez MJ, Vazquez-Casielles R (2020) Is showrooming really so terrible? Start understanding showroomers. J Retail Consum Serv. https://doi. org/10.1016/j.jretconser.2020

von Briel F (2018) The future of omnichannel retail: a four-stage delphi study. Technol Forecast Soc Chang 132:217-229

Wang C, Leng M, Liang L (2018) Choosing an online retail channel for a manufacturer: Direct sales or consignment? Int J Prod Econ 195:338-358

Wiener M, Hoßbach N, Saunders C (2018) Omnichannel business in the publishing and retailing industries: synergies and tensions between coexisting online and offline business models. Decis Support Syst 109:15-26

Wilson M (2017) Online or offline? Report Looks at Future of 13 Retail Categories, Available at https://chainstoreage. com/news/online-or-offline-report-looks-future-1-retail-ca tegories, Last accessed on October 10, 2021

Wohlsen M (2012) Walmart.com CEO: we embrace showrooming, Wired, November 23, Available at https://www. wired.com/2012/11/walmart-embraces-showrooming/, Last accessed on October 10, 2021

Wu D, Ray G, Geng X, Whinston A (2004) Implications of reduced search cost and free riding in E-commerce. Mark Sci 23(2):255-262

Xing D, Liu T (2012) Sales effort free riding and coordination with price match and channel rebate. Eur J Oper Res 219:264-271 
Zhang P, He Y, Shi C (2017) Retailer's channel structure choice: Online channel, offline channel, or dual channels? Int J Prod Res 191:37-50

Zhang S, Zhang J (2020) Agency selling or reselling: E-tailer information sharing with supplier offline entry. Eur J Oper Res 280:134-151

Zhang T, Li G, Cheng TCE, Shum S (2020) Consumer interproduct showrooming and information service provision in an omni-channel supply chain. Decis Sci 51(5):1232-1264

Zhang S, Yao Y, Zhang J (2021) Consumer showrooming with supplier encroachment and omnichannel retailing. Decisn Sci. https://doi.org/10.1111/deci.12539
Zhou Y-W, Guo J, Zhou W (2018) Pricing/service strategies for a dual-channel supply chain with free riding and servicecost sharing. Int J Prod Econ 196:198-210

Zimmerman A (2012) Can Retailers Halt 'Showrooming'"?. The Wall Street J, April 11, Available at https://www.wsj. com/articles/SB10001424052702304587704577334370 670243032, Last accessed on October 10, 2021

Publisher's Note Springer Nature remains neutral with regard to jurisdictional claims in published maps and institutional affiliations. 